\title{
وعي الشباب بموارده البشرية وعلاقته بجودة إنتاج المشروعات الصغيرة
}

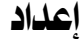 \\ أ. م.ه. حناطـ سامحسـ محمد عبد العاطحس. \\ أستاذ مساعد بقسه إدارة مؤسسات الأسرة والطفولة \\ كلية الاقتصاد المنزلي - جامعة حلوان
}

مجلة بحوث التربية النوعية ـ جامعة المنصورة

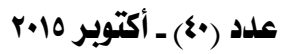




\section{وعي الشباب بموارده البشرية وعلاقته بجودة إنتاج المشروعات الصغيرة}

$$
\text { إعداد }
$$

أ. .د . .حنازسامرمحمد عبد العاطي

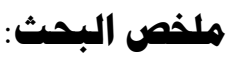

تهــف الدراســة الحاليـة إلى الكـشف عـن العلاقــة بـين وعـي الـشباب العـاملين بالمشـروعات

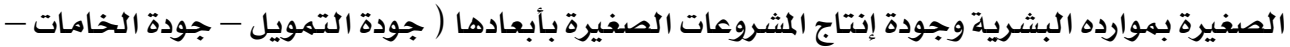

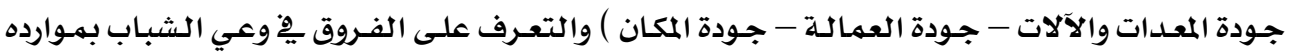

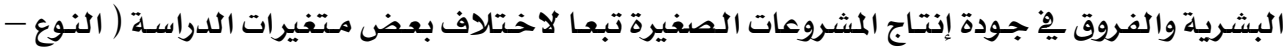

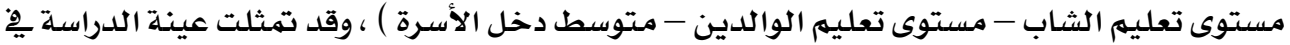

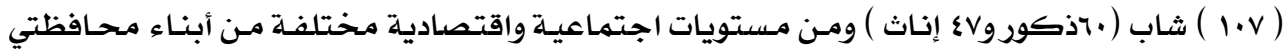

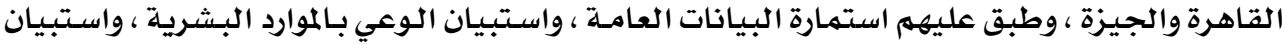

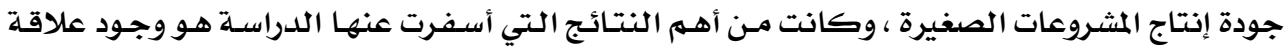

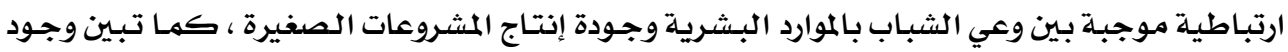

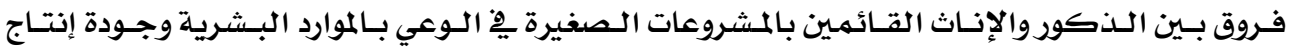

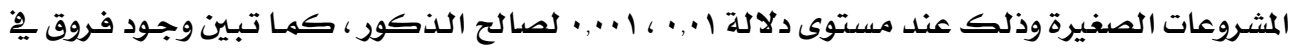

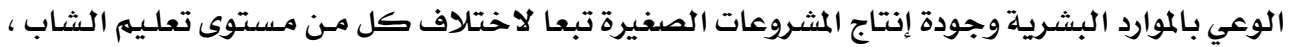

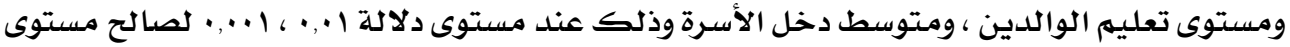

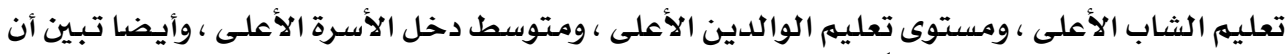

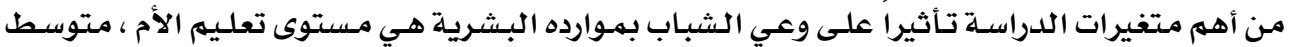

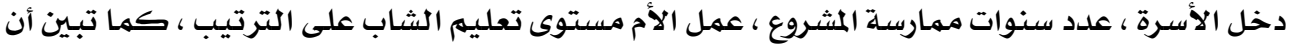

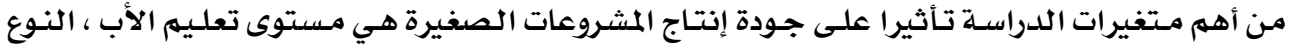

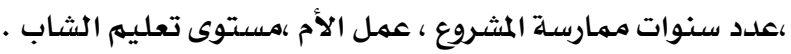

\section{مقدهة ومشكلة البمث :}

تعـد المشروعات الصغيرة إحـدى مـشروعات التنميـة التي تتبناهـا وتـدعمها الكثير مـن الدول

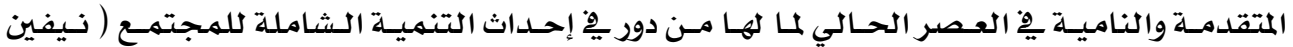

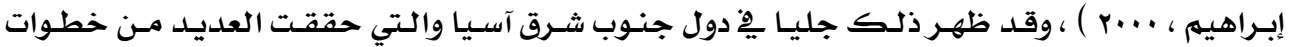

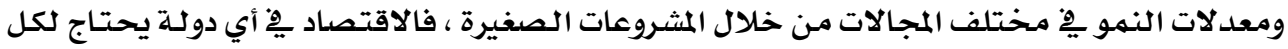

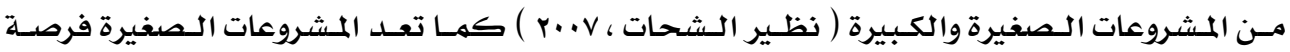




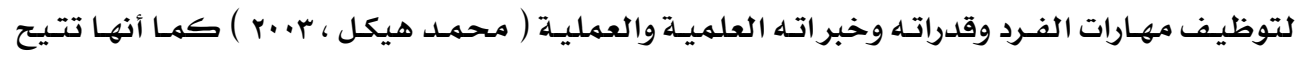
فرص عمل أكثر فِ ظل أزمهة البطالة الخانقة ( ثابت إدريس ، 11 •r ). وقـد أثـارت العديـد مـن الدراسـات إلى أهميـة المشـروعات الصغيرة يخ عمليـة التتنميـة ومنهـا

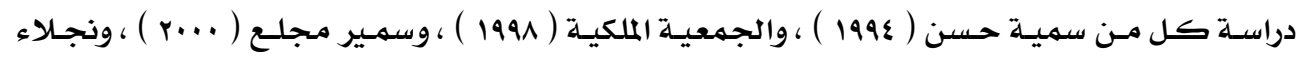

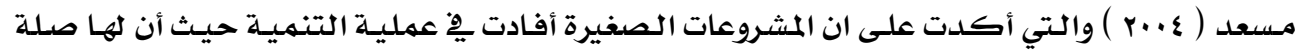

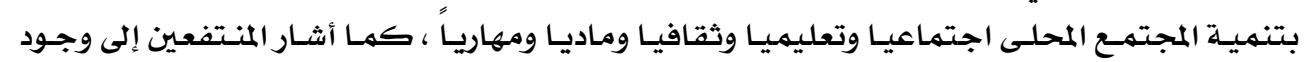

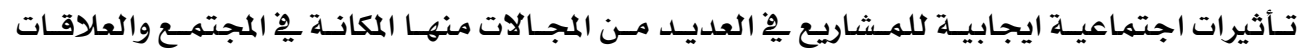
الاجتمهاعية وزيـادة الثقة بالنفس وزيـادة الوعي بشؤون الأسـرة . ولكي يتحقق النجاح لمثل هذه المشروعات الصغيرة وتحقق المزيد من عملية التنهيـة لابـد وأن يتوافر بها مقومـات الكفاءة والجودة ، وهو ما يتطلب أن تأتي هذه المشروعات ملبيـة لاحتياجـات المجتمـع

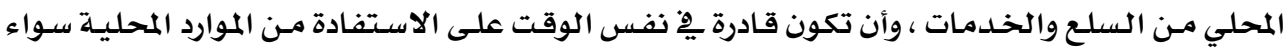

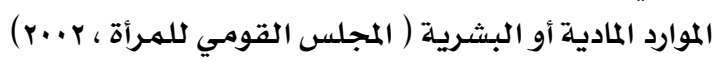
فالاتجـاه نحـو الاهتمـام بالإنتـاج وجـودة السـلـع والخـلـمـات بهـا يلـبي احتياجـات المستهلك

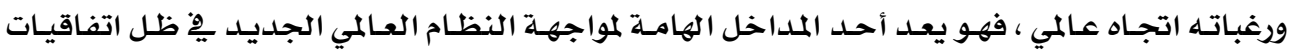
الشراكة واستراتيجيات التجارة الدولية ( Michalasr \& M.E.Brain . وعلى الرغم من أهميـة تحقيق الجودة الإنتاجية للمشروعات الصغيرة لدفع عجلـة التنميـة ، ومسـايرة النظم العالمية إلا أنه قد تبـين من خلال العديد من الدراسـات أن المشـروعات الصغيرة مـا زالت تواجه الكثير من المشكلات والتي تقلل من فرص نجاحها ومنها القصور النسبي يْ جودة وكفاءة تلك المشروعات ، فنجد دراسـة 1991 (Donald,W. قد أثـارت إلى أن قلة الأفكار والمعلومات والخبر ات مـن

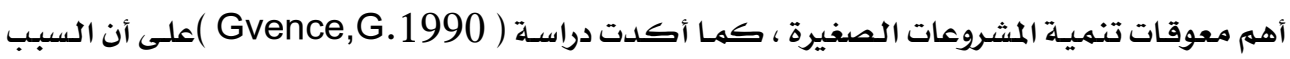
الرئيسي وراء فشل المشـروعات الصغيرة يرجـع إلى عدم صسلاحية وكفـاءة الإدارة ، وأثبتت دراسـة ياسـر

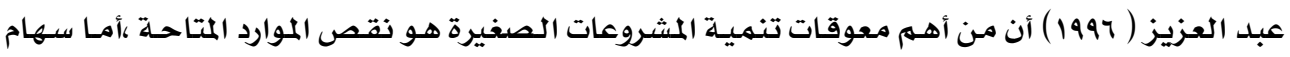

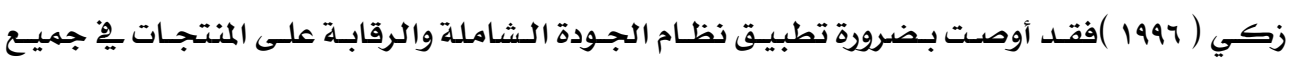

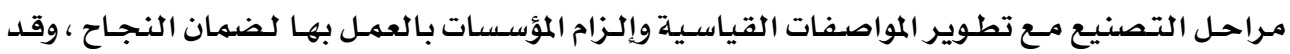

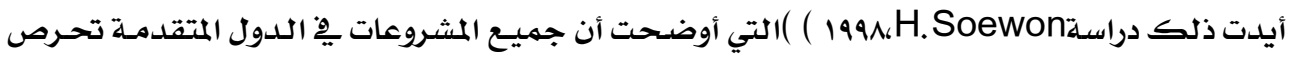
على تطبيق أنظمة الأيزو ، . .9 ، بدرجة أكبر من الدول الناميـة مها يجعلها الأكثر تقدما ونجاحا .

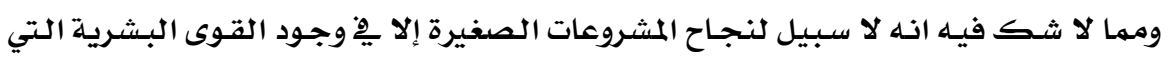

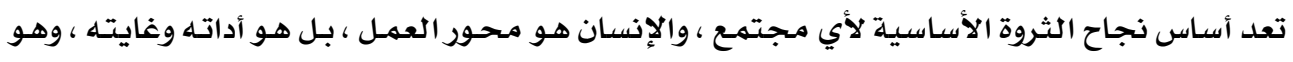

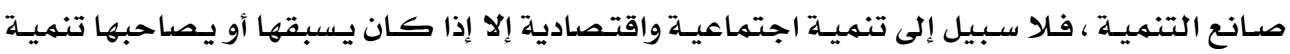
بشريـة قوامها الإنسـان (سهام زكي ، 1991 ) ، والتتميـة البشريـة هي المنهج الـذي يهتم بتحسيسين نوعيـة

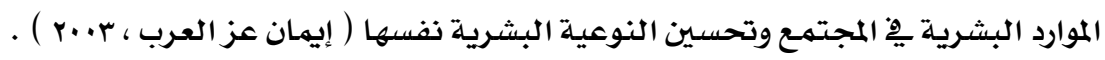


والشباب هم أكثر فئكات القوى البشرية قدرة على العطاء والرغبـة يِّ تحقيق الدات واثبات

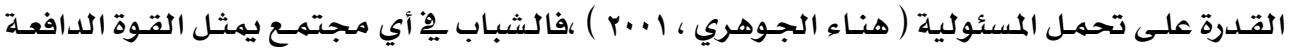

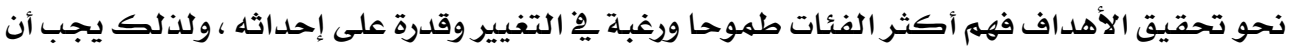

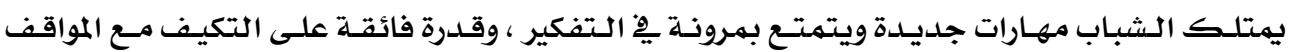
واتخاذ القرار على أسس علمية كذلك القدرة على التحول من مهمة لأخرى ، وأن يكون على مستوى الته

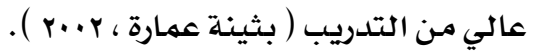

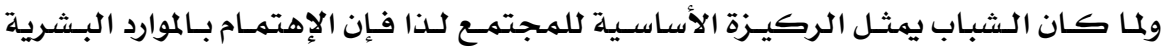

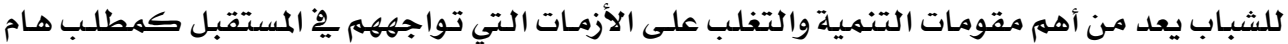

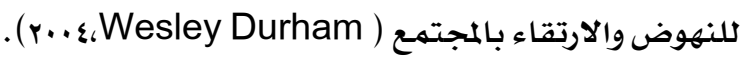

وإدراكا لأهميـة الموارد البشريـة للشباب أجريـت بعض الدراسـات التي أكسدت على أهميـة

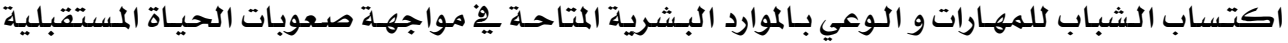

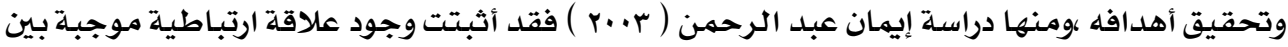

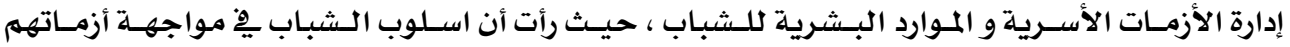

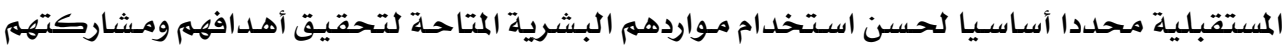
الإيجابية لمسئولياتهم.

ونظرا لان الشباب يمتلكون العديد مـن الموارد البشرية ، مـع إهمال أغلب الشباب لتلك المباب الموارد

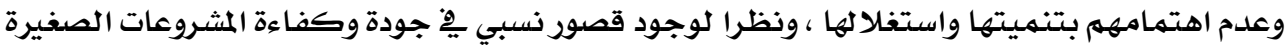
طبقا لما ورد بالدراسـات السابقة ، وجدت الباحثة حاجـة ملحسة تلدعو لدراسـة العلاقـة بـين وعي الشباب

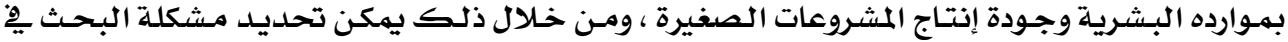

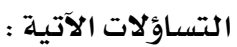

• ما هي العلاقة بين وعي الشباب بموارده البشرية وجودة إنتاج المشروعات الصغيرة ؟

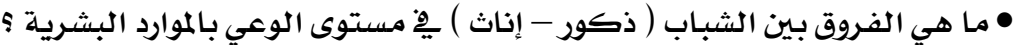

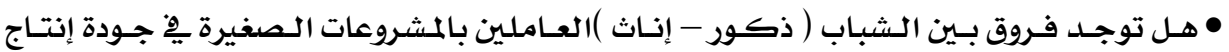

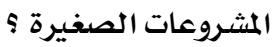

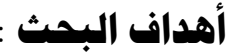
يهدف البحث الحالي إلى الكشف عن العلاقة بين وعي الشباب بموارده البشرية وجـودة إنتاج المشروعات الصغيرة وذلك من خلال :

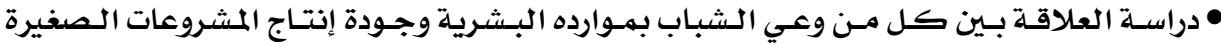

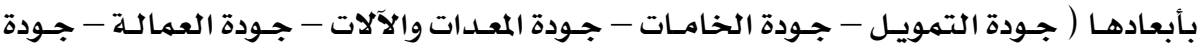

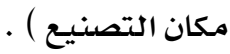
• التعرف على الفروق ِِّ وعي الشباب ( ذكور - إناث ) العـاملين بالمشروعات الصغيرة يِّ الوعي 
• الكثف عن الفروق بين الشباب ( ذكور - إناث ) العـاملين بالمشروعات الصغيرة فى جـودة إنتاج

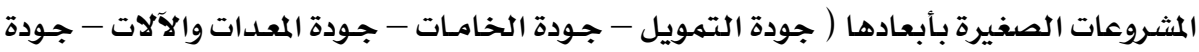

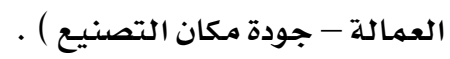

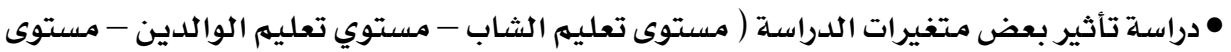

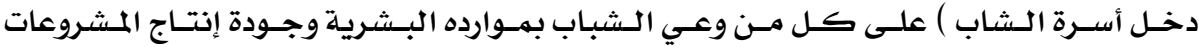

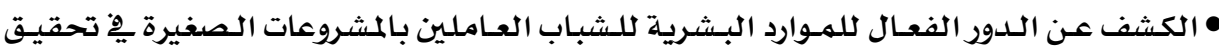

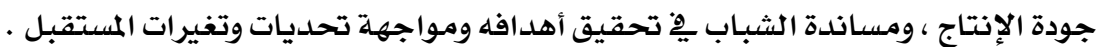

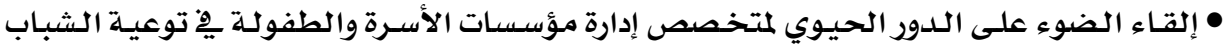

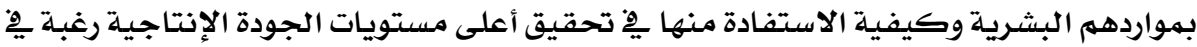

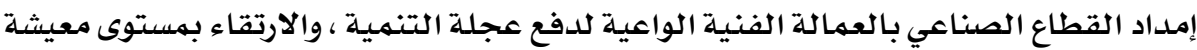
الأسـرة .

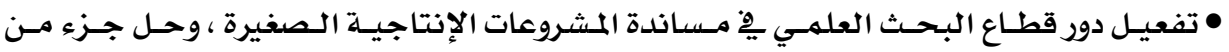

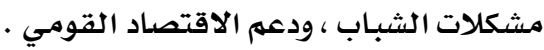

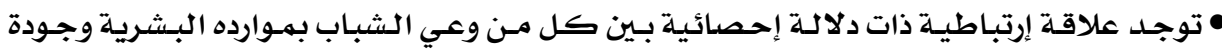

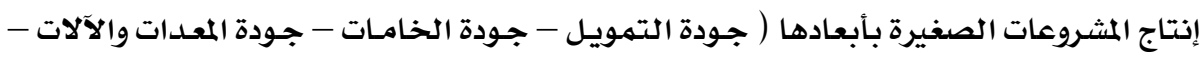

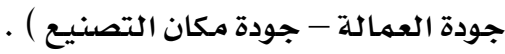

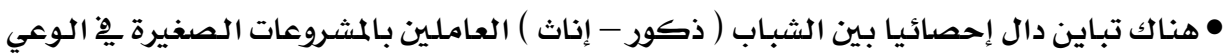

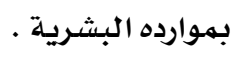

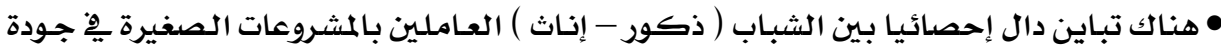

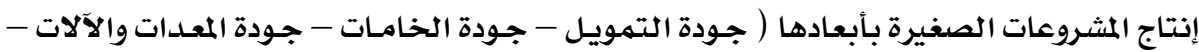

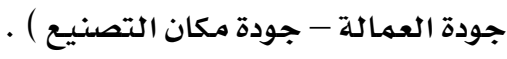

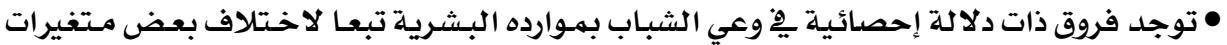

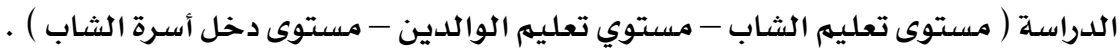

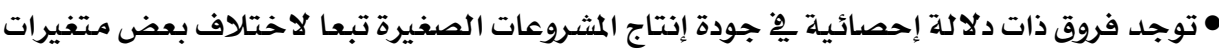

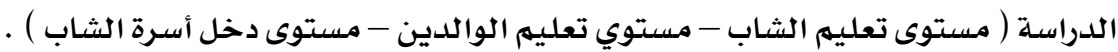

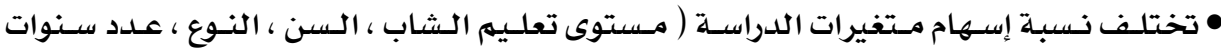

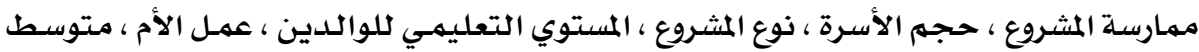

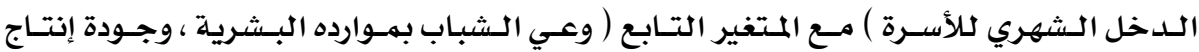

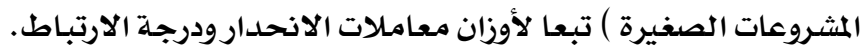




\section{الأسلوب البحثي :}

أولا : المقاهيم العلمية والإجرائية للبحث :

•

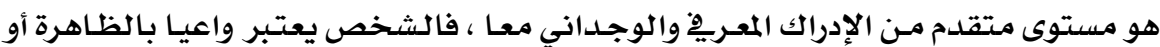

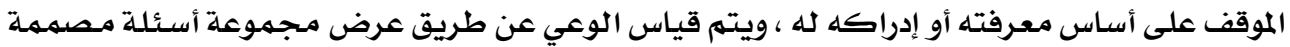

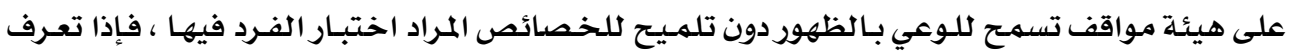

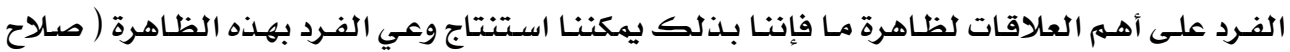

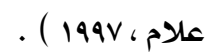

\section{•}

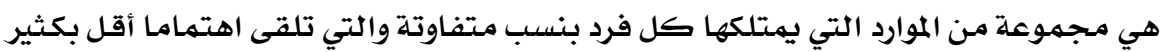

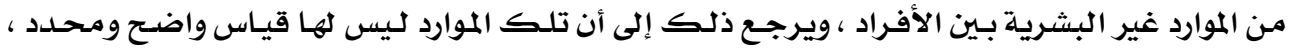

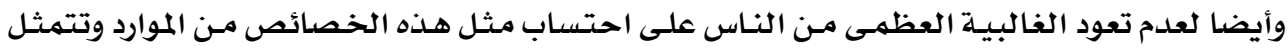

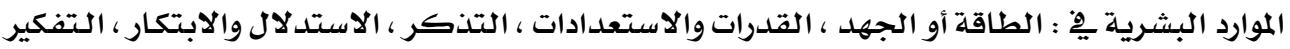

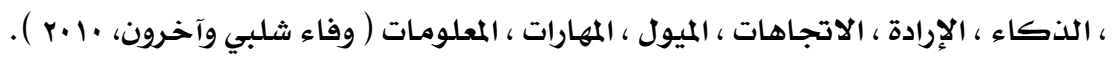

•

هي مرحلـة يتميز فيها الشـاب بحصوله على الاسـتلال عن الأسـرة وحصوله على العمـل

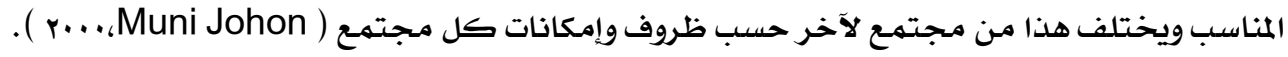

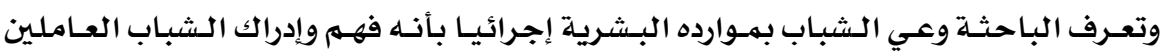

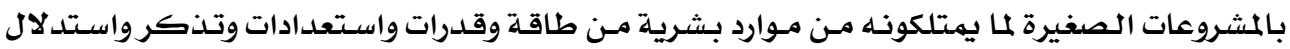

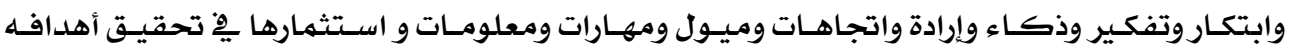

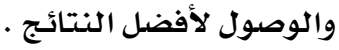

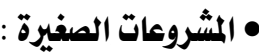

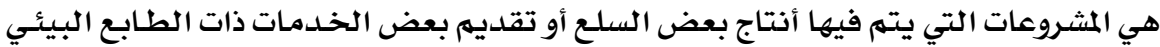

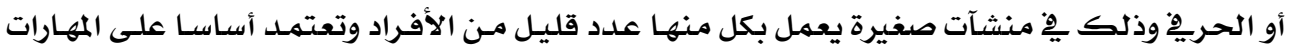

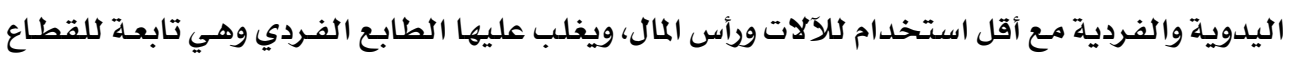

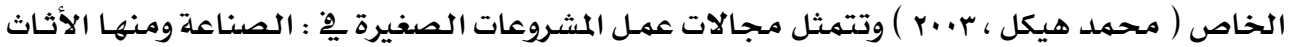

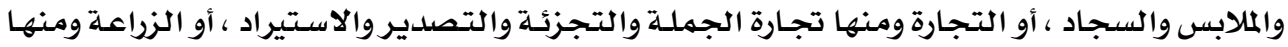

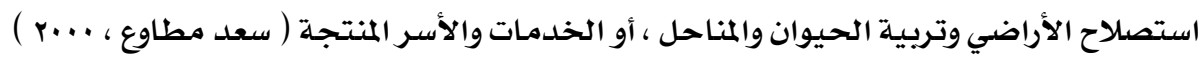




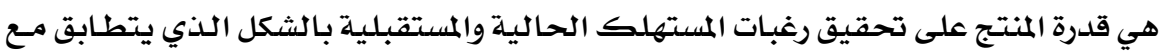

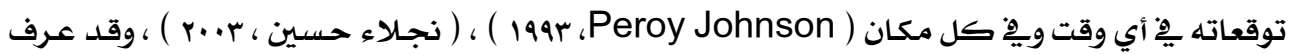

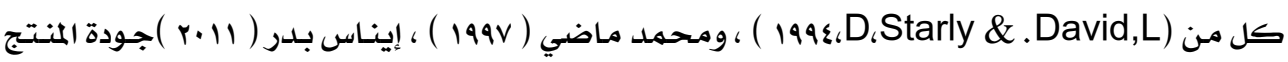

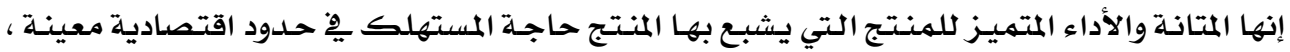

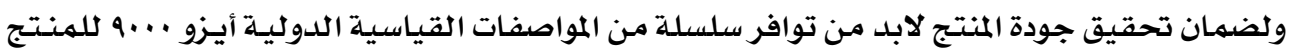

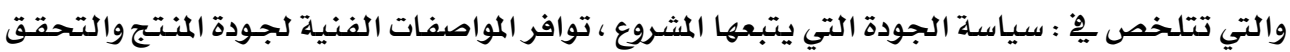

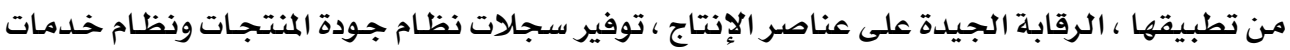

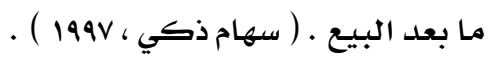

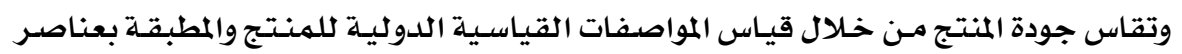

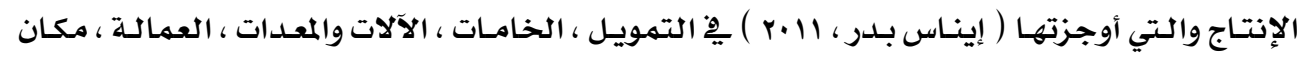
التصنيع ). وتعرف الباحثة جودة إنتاج المشروعات الصغيرة إجرائيا بأنها درجـة كفـاءة إنتاج المشروعات

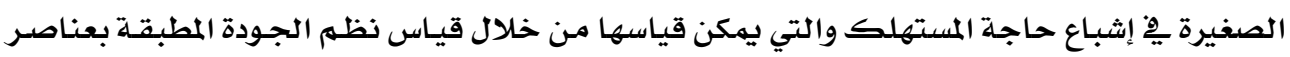

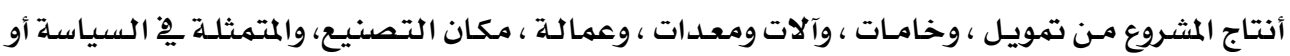

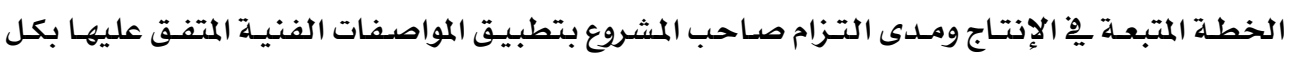

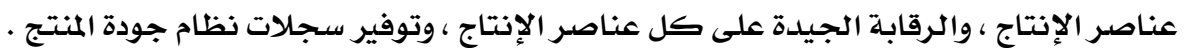
ثانيا : منهج البحث :

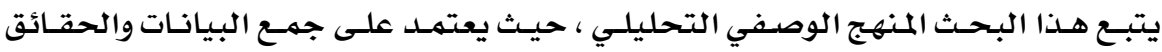

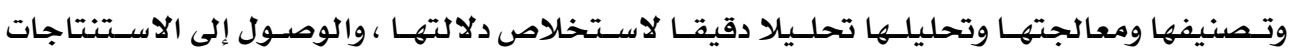

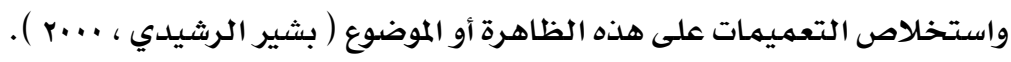

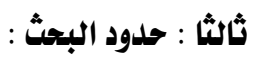

$$
\text { يتحدد البحث الحالي بما يلي : }
$$

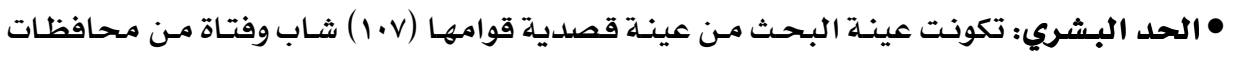

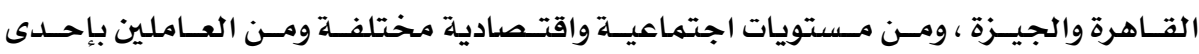

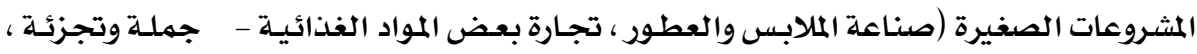

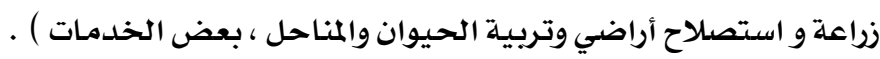

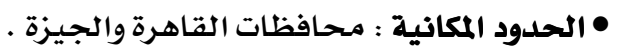

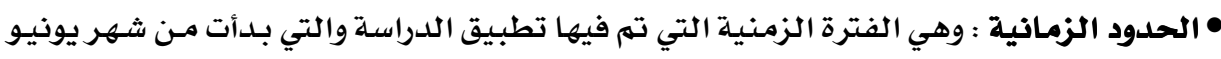

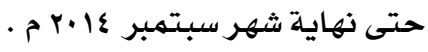




$$
\begin{aligned}
& \text { رابعا : أدوات البحث : ( إعلداد الباحثة ) }
\end{aligned}
$$

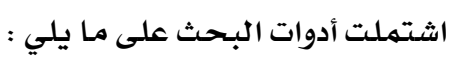

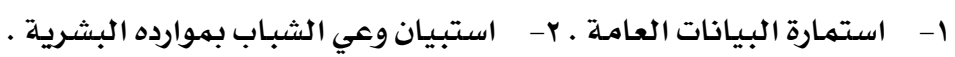

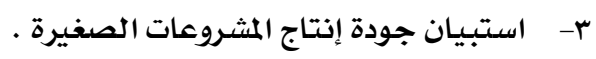

$$
\begin{aligned}
& \text { 1- استمارة البيانات العامهة : }
\end{aligned}
$$

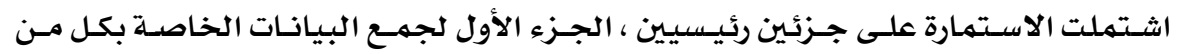

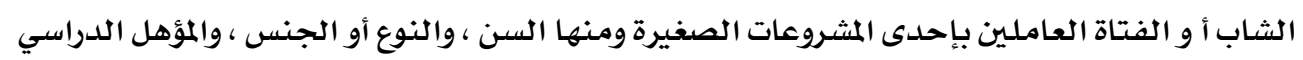

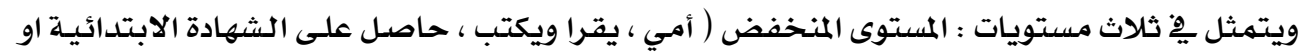

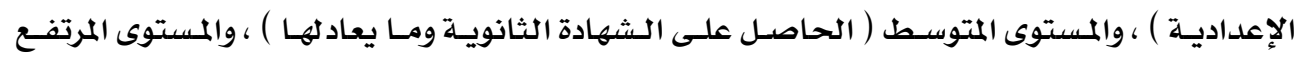

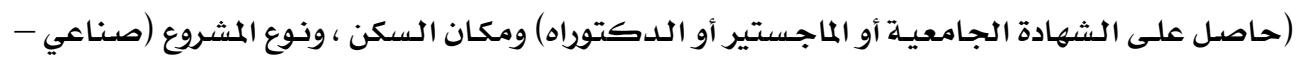

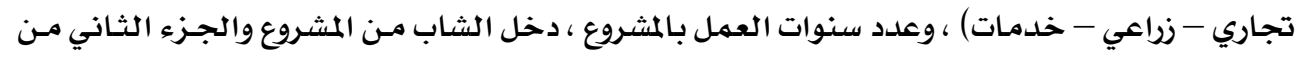

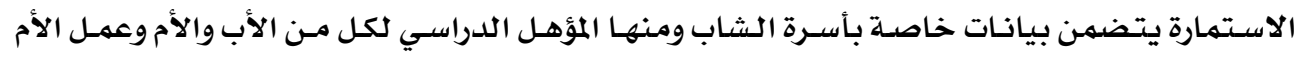

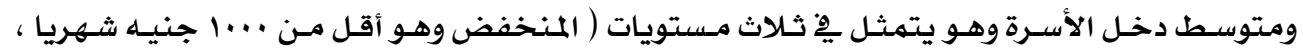

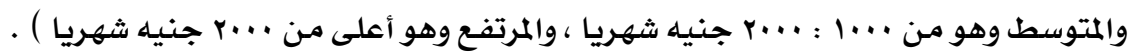

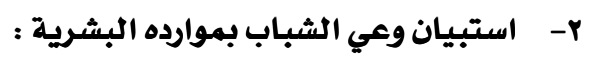

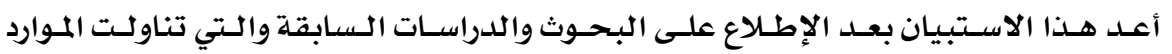

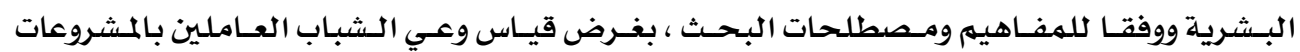

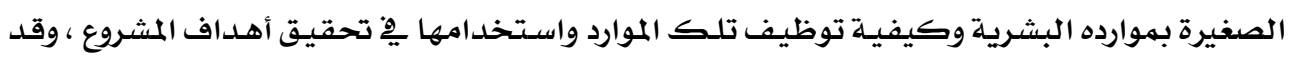

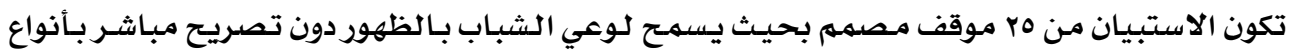

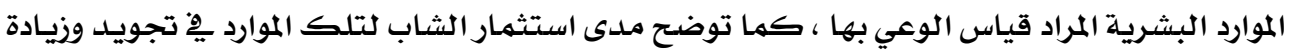

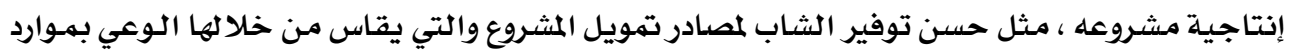

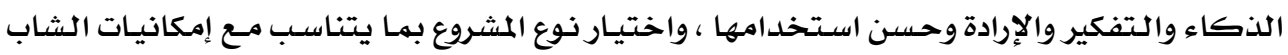

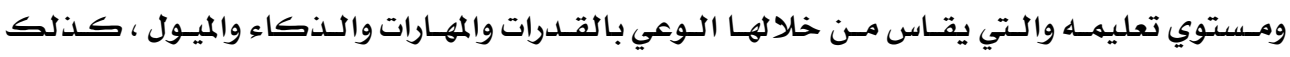

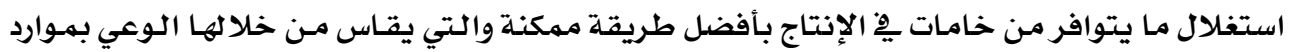

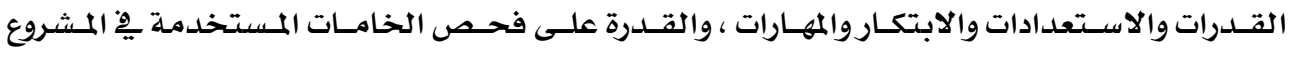

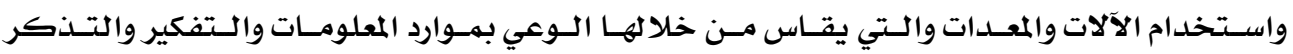

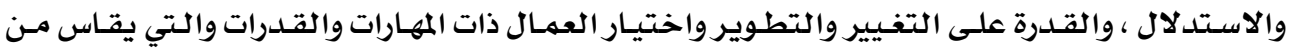

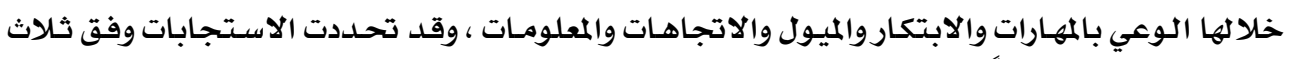

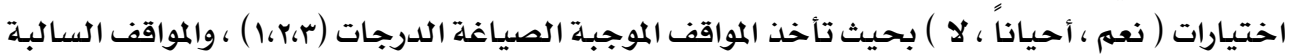

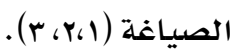




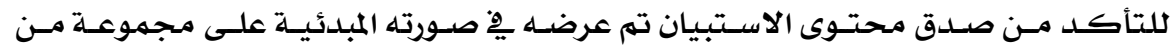

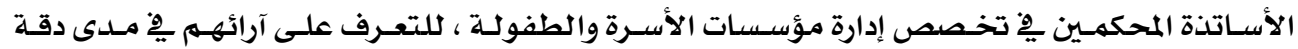

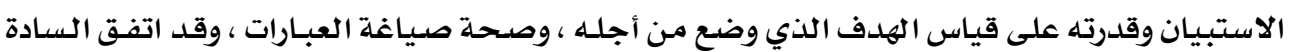

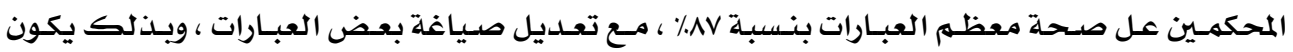
الاستبيان قد خضع لصدق المحتوى . ثبات الاستبيان:

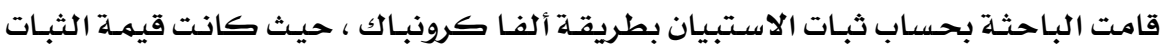

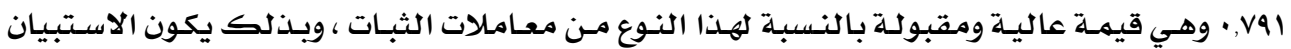
صالحا للتطبيق

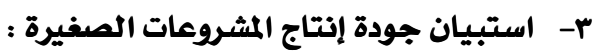

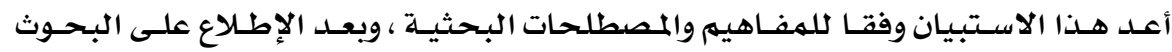

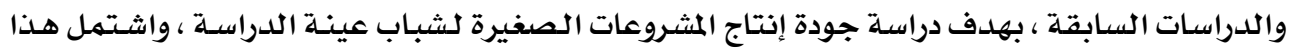

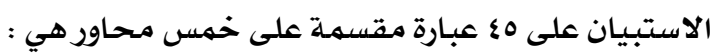

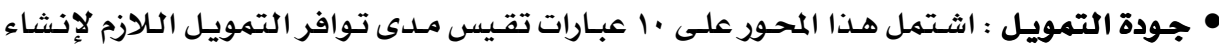

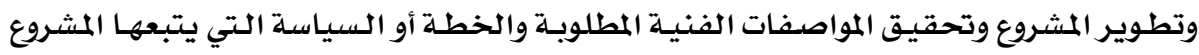

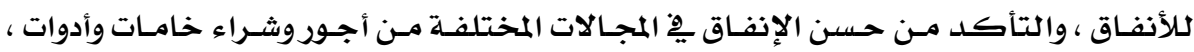

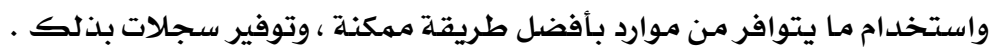

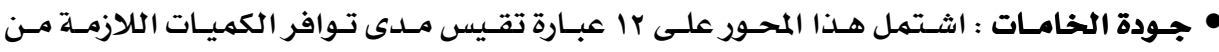

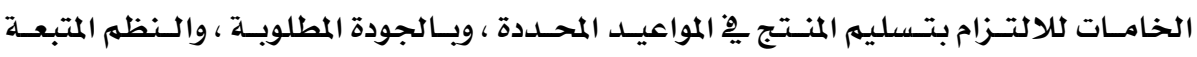

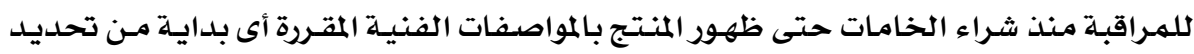

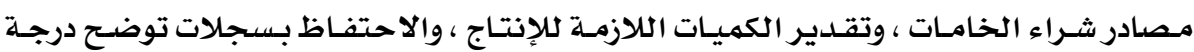

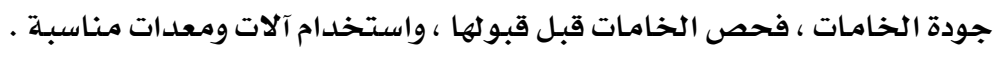

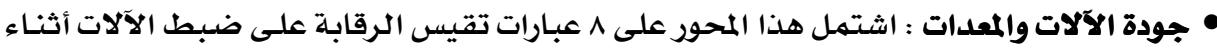

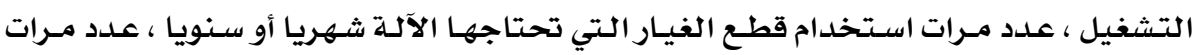

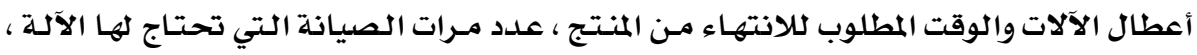

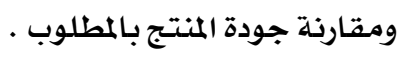

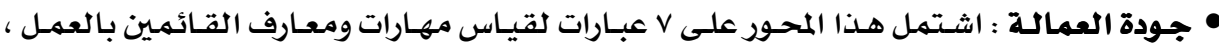

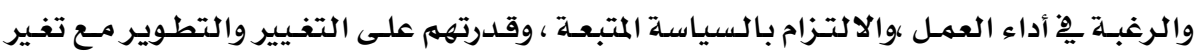

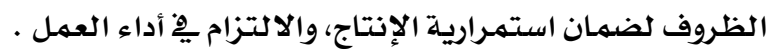

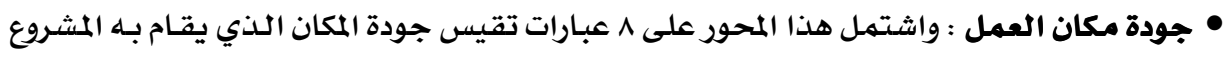

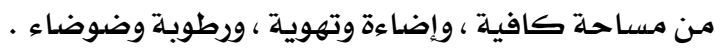




\section{صدق المقياس :}

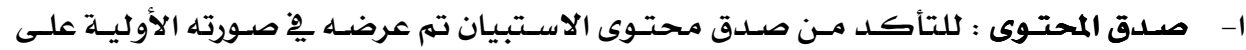

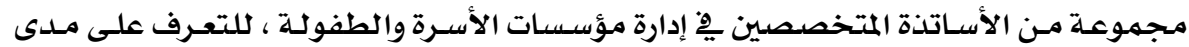

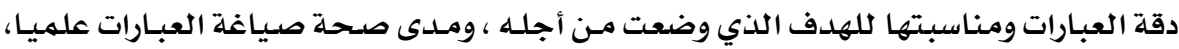

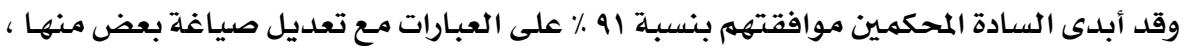

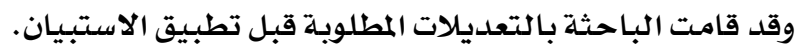

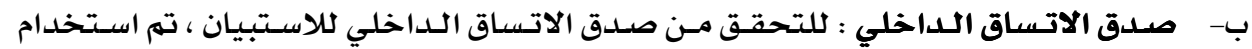

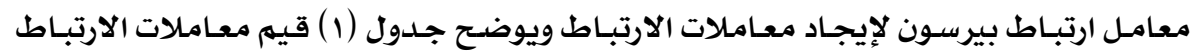

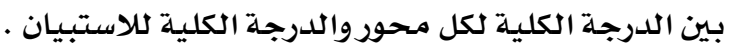
جدول (1) قيم معاملات الارتباط بين درجة كل محور من محاور استبيان جودة انتاج المشروعات الصغيرة والدرجة الكلية للاستبيان

\begin{tabular}{|c|c|c|}
\hline الدلادة & الارتباط & مححاور الاستبيان \\
\hline$\cdot, \cdot 1$ & $\cdot, 9 \varepsilon$ & جودة التمويل \\
\hline$\cdot, \cdot 1$ & $\cdot, \Lambda \vee$ & جودة الخامات \\
\hline$\cdot, \cdot 1$ & $\cdot, \mathrm{VV}$ & جودة المعدات والآلات \\
\hline$\cdot, \cdot 1$ & • & جودة العمالة \\
\hline$\cdot, \cdot 1$ & .91 & جودة المكان \\
\hline
\end{tabular}

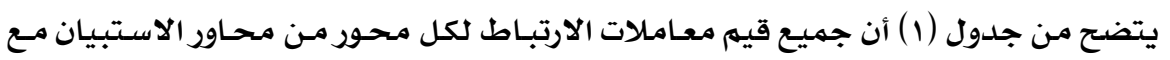

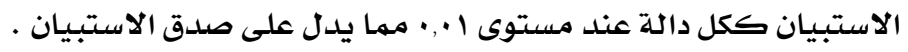
ثبات الاستبيان :

قامت الباحثة بحساب ثبات الاستبيان بطريقة ألفا كرونباك كهما هو موضح بجدول (r) جدول (r) معامل الثبات لمحاور استبيان جودة انتاج المشروعات الصغيرة

\begin{tabular}{|c|c|c|c|c|c|c|}
\hline جودة الاستبيان & المكان & العمالة & جودت الآلات & جودة & جتودة التمويل & محاور الاستبيان \\
\hline • & • & $\cdot 9 \mathrm{r}$ & $\cdot, \wedge 1$ & $\cdot, \Lambda \Lambda$ & •, 14 & قيهم معامـلات الثبـات \\
\hline
\end{tabular}

يتضـح من جدول (r) أن قيم معاملات الثبات كانت عالية بالنسبة لهـذا النـوع مـن معـاملات

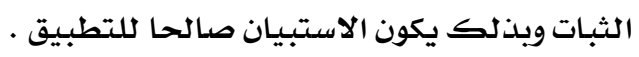




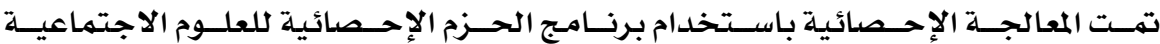

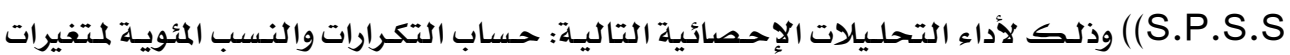

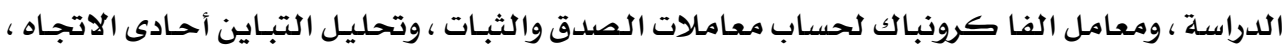

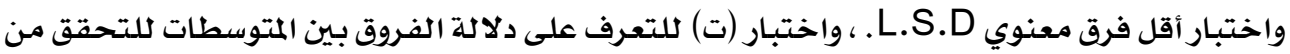
صحة فروض الدراسـة .

\section{النتائج تطليلها وتفسيرها :}

أولا :وصف عينة الدراسة :

جدول ( r ) توزيع عينة الدراسة وفقا لمتغيرات الدراسة

$(1 \cdot v=0)$

\begin{tabular}{|c|c|c|c|c|c|c|c|c|c|}
\hline النسبة . & | التكرار & الفئات & المتفيرات & P & النسبة \% & التكرار & الفئات & المتفيرات & A \\
\hline $\begin{array}{l}11, r \\
r q, 9 \\
0 \wedge, 9\end{array}$ & $\begin{array}{l}\text { Ir } \\
\text { rr } \\
T r\end{array}$ & 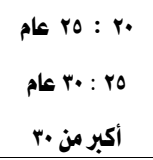 & عمر الشاب أو الفتاة & r & $\begin{array}{l}07,1 \\
27, q\end{array}$ & $\begin{array}{l}9 . \\
\text { sY }\end{array}$ & إناث & النوع ل & 1 \\
\hline $\begin{array}{l}1 \Lambda, Y \\
\varepsilon \wedge, Y \\
r Y, Y\end{array}$ & $\begin{array}{l}\text { r. } \\
\text { or } \\
\text { ro }\end{array}$ & أقأ أقل من عام أعوام & عدد سنوات ممارسة & $\varepsilon$ & $\begin{array}{l}\varepsilon r, Y \\
o r, r\end{array}$ & $\begin{array}{l}01 \\
07\end{array}$ & متوسط & مستوى تعليم & $r$ \\
\hline $\begin{array}{l}r r, \xi \\
\xi \varphi, r \\
1 A, Y \\
M A, Y\end{array}$ & $\begin{array}{l}\text { rq } \\
\varepsilon r \\
r . \\
r .\end{array}$ & خلجارة & نوع الشروع & 1 & $\begin{array}{l}l A, Y \\
\varepsilon Y, Y \\
r r, Y\end{array}$ & $\begin{array}{l}\text { r. } \\
01 \\
\text { ra }\end{array}$ & أقل من ..0 جنيه & متوسط دخل الشاب | & 0 \\
\hline $\begin{array}{l}r r, \xi \\
0 \cdot, 0 \\
r Y, 1\end{array}$ & $\begin{array}{l}r \xi \\
o \xi \\
r q\end{array}$ & متخفض متوسط & مستوى تعليم الام & $\wedge$ & $\begin{array}{l}11,1 \\
\Delta 0, r \\
r r, Y\end{array}$ & $\begin{array}{l}14 \\
09 \\
r q\end{array}$ & متخفض متوسط & مستوى تعليه الأب & v \\
\hline $\begin{array}{l}v, 0 \\
0 \wedge, q\end{array}$ & $\stackrel{4}{i r}$ & متخفض متوسط & متوسط دخل الاسرة & 1. & $\begin{array}{l}01, \xi \\
\{\Lambda, 7\end{array}$ & $\begin{array}{l}\text { oo } \\
\text { or }\end{array}$ & غير عاملة عاملة & عمل الام & 9 \\
\hline$r r, q$ & rq & عالي & & & $\begin{array}{l}r q, q \\
r q, \xi \\
r r, v\end{array}$ & $\begin{array}{l}r r \\
r q \\
r q\end{array}$ & متوسط & حجم الأسرة & 11 \\
\hline
\end{tabular}


يتضح مـن جـدول ( r ) أن أكثر مسن نصف عينـة الدراسـة مـن الدذكور حيـث بلغت نسبتهمه

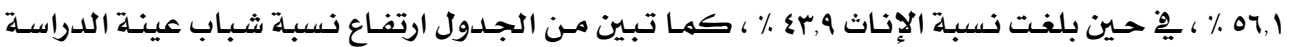

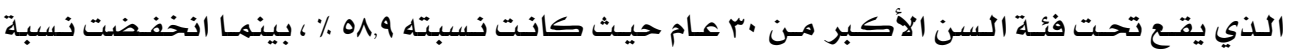

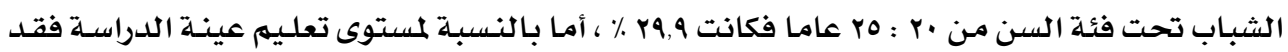

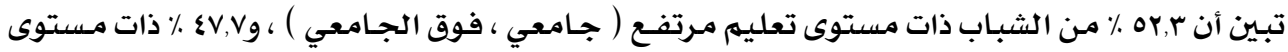

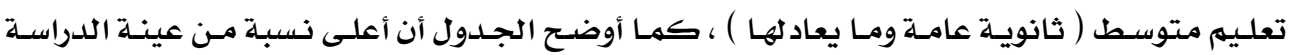

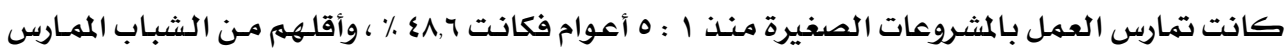

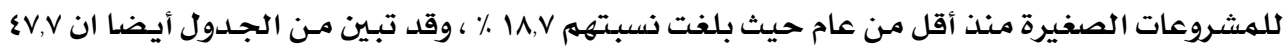

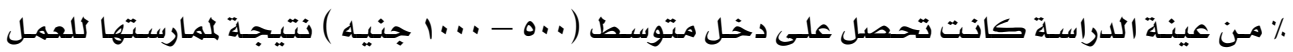

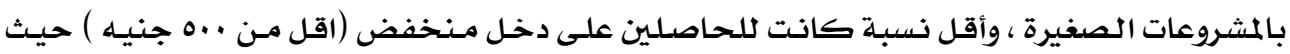

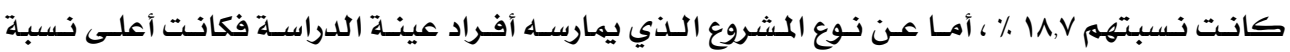

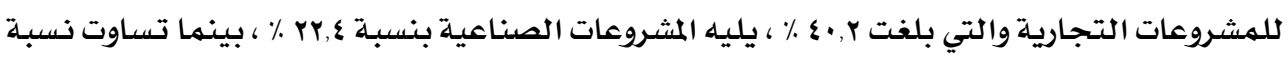

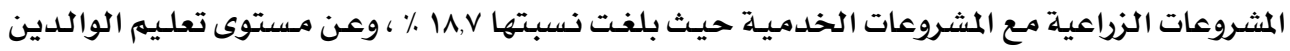

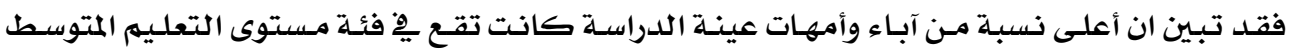

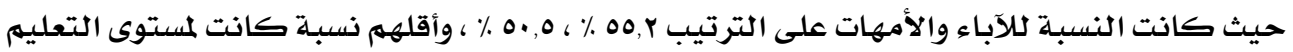

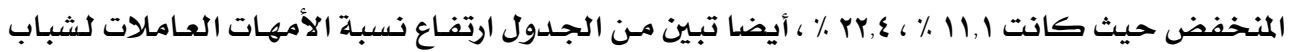

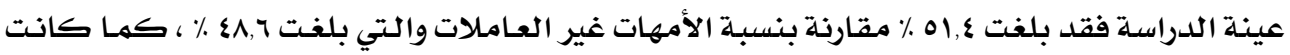

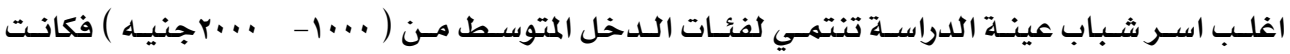

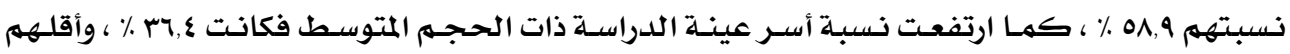

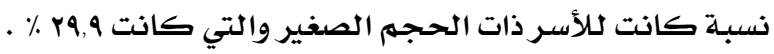

ثانيا : النتائج في ضوء فروض اللدراسة :

الفرض الأول : توجد علاقة إرتباطية ذات دلالة إحصائية بين كل من وعي الشباب بموارده

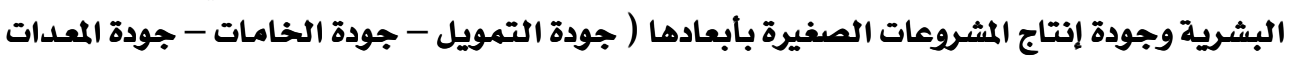

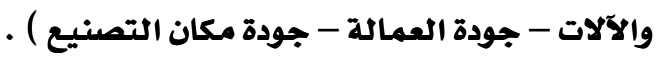

وللتحقق من صحسة هذا الفرض تم إيجاد مصفوفة معاملات الإرتباط بين المتغيرات .

جدول ( ع )مصفوفة معاملات الإرتباط بين وعي الشباب بموارده البشريـة

وجودة إنتاج المشروعات الصغيرة بأبعادها

\begin{tabular}{|c|c|c|c|c|c|c|}
\hline جودة الإتتاج & جودة المكان & جودة العمالة & جودة المعدات والآلات & جودة الخامات & جودة التمويل & المتفيرات \\
\hline * & $*$, , T\&Y & $*$, , $1 \leqslant 9$ & $*, 707$ & $*,, 7 r 1$ & $*_{\cdot, \text { tar }}$ & وعي الشباب بهوارده البشرية \\
\hline
\end{tabular}

*دال عند مستوى دلالة ا..,.. 
أوضـح جدول ( ) ) وجود علاقـة أرتباطيـة موجبـة بـين كل مـن وعي الشبـاب بهـوارده البشريـة

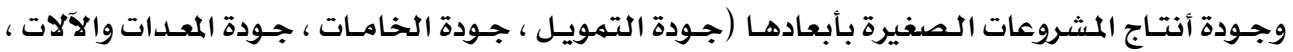

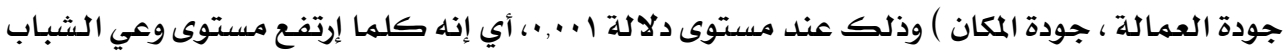

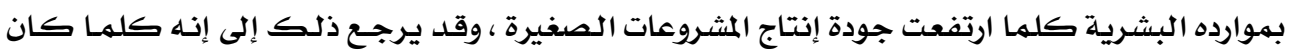

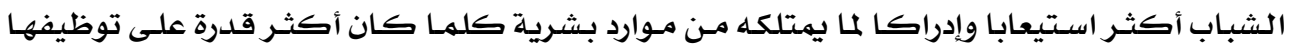

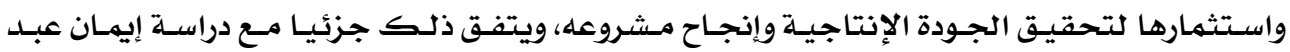

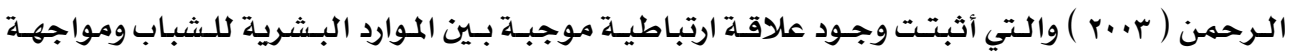

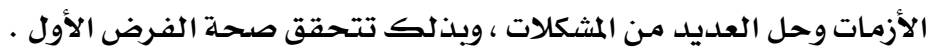

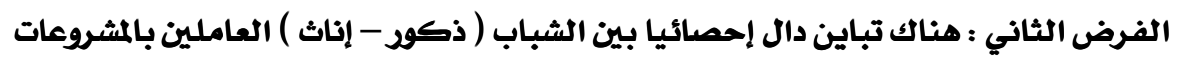

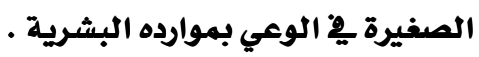
وللتحقق مـن صـحة هـذا الفـرض تم إجـراء تحليـل التبـاين ، واختبـار( ت ) كمهـا هو موضـح

بجدول (ه) ( ب)

جدول (ه) تحليل التباين بين الذكور والإناث يِّ الوعي بالموارد البشرية

\begin{tabular}{|c|c|c|c|c|c|c|}
\hline مستوى الدلالة & قيمة ف & متوسط المربعات & مجموع المربعات & درجات الحرية & مصلدر التباين & المتفيرات \\
\hline$\cdot, \cdot 1$ & $0, r$ & $\begin{array}{l}10 \gamma, y \\
r \cdot, r\end{array}$ & $\begin{array}{l}\text { lov, } 1 \\
\text { rirr,q } \\
\text { rrri,o }\end{array}$ & $\begin{array}{c}1 \\
1.0 \\
1.7\end{array}$ & داخل المجلمجات المجموعات & البشرية للشباب \\
\hline
\end{tabular}

تبين من خلال جدول (ه) وجود فروق ذات دلالة إحصائية بـين ذكور وإناث عينـة الدراسـة يِ

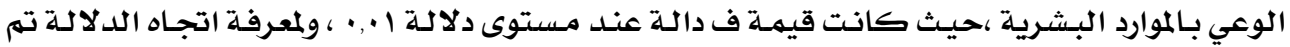

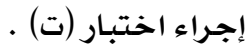

جدول (ج)الفروق بين الذكوروالإناث بِّ الوعي بالموارد البشرية

\begin{tabular}{|c|c|c|c|c|c|c|}
\hline اتجاه الدلالة & مستوى الدلالة & قيعة ت & الخطأ المعياري & الانحراف المعياري & المتوسط الحسابي & المتفيرات \\
\hline \multirow[t]{2}{*}{ لصالح الذكور } & $\cdot, \cdot 1$ & $r, r A$ & $\cdot, n$ & $7, r$ & $r r, \leqslant \eta$ & ذكور \\
\hline & & & $\cdot, \Lambda \cdot$ & $\S, 0$ & $r \cdot, \cdot r$ & اناث \\
\hline
\end{tabular}

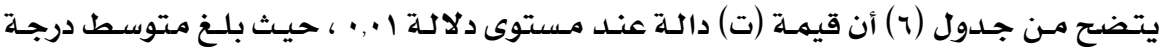

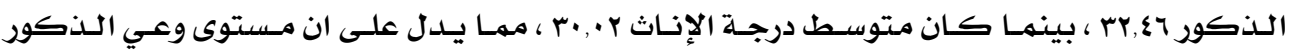

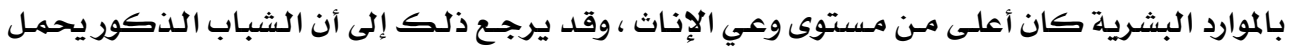

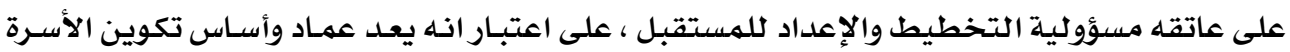

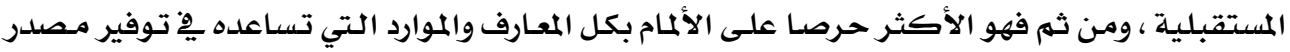

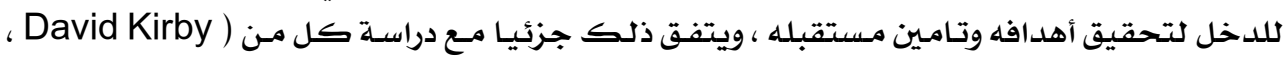




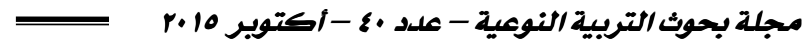

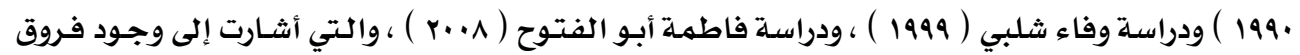

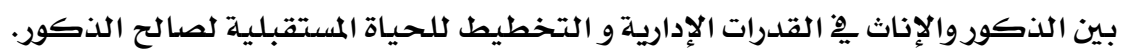

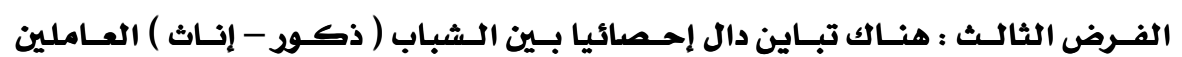

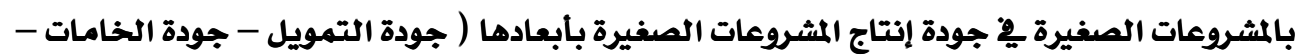

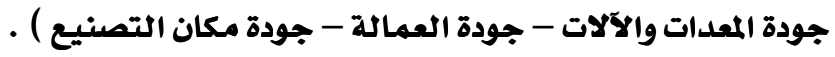
وللتحقق من صحة هذا الفرض تم إجراء تحليل التباين ( اختبار. ف) للتعرف على الفروق.

\begin{tabular}{|c|c|c|c|c|c|c|}
\hline مستوى الدلالة & قيمة ف & متوسط المربعات & مجموع المربعات & درجات الحرية & مصدر التباين & المتفيرات \\
\hline غير دالة & $\cdot, 10$ & $\begin{array}{l}r, \cdot 0 \\
19, v 4\end{array}$ & $\begin{array}{c}r, \cdot 0 \\
r \cdot v \varepsilon, \Delta 0 \\
r \cdot v r, \eta 1\end{array}$ & $\begin{array}{c}1 \\
1.0 \\
107\end{array}$ & داخل المجموعات المجموعات & جودة التمويل \\
\hline$\cdot, \cdot \cdot 1$ & $i r, r v$ & $\begin{array}{l}r 9 \cdot, 7 r \\
19,89\end{array}$ & $\begin{array}{l}r q \cdot, q r \\
r \cdot \xi v, r \varepsilon \\
r r \cdot v, q q\end{array}$ & $\begin{array}{c}1 \\
1.0 \\
107\end{array}$ & داخل المجموعات المجموعات & جودة الخامات \\
\hline$\cdot, \cdot \cdot 1$ & 9,70 & $\begin{array}{l}\{Y, \xi 0 \\
\xi, q r\end{array}$ & $\begin{array}{l}2 Y, \xi 0 \\
017, r 1 \\
07 r, 77\end{array}$ & $\begin{array}{c}1 \\
1.0 \\
107 \\
\end{array}$ & داخل المجل المجموعات & جودة المعدات \\
\hline غير دالة & $1, r 9$ & $\begin{array}{l}0, \& 9 \\
\varepsilon, \mathrm{rv}\end{array}$ & $\begin{array}{c}0,\{q \\
\{09,1 \varepsilon \\
\{7 \varepsilon, 7 \varepsilon\end{array}$ & $\begin{array}{c}1 \\
1.0 \\
107\end{array}$ & داخل المجن المجموعات & جودة العطالة \\
\hline$\cdot, \cdot \cdot 1$ & $r q, r \xi$ & $\begin{array}{l}1 \cdot \delta, 7 \gamma \\
r, 01\end{array}$ & $\begin{array}{l}1 \cdot \xi, 7 Y \\
r Y O, \wedge \Lambda \\
\{\Lambda \cdot, 0\rceil\end{array}$ & $\begin{array}{c}1 \\
1.0 \\
107\end{array}$ & داخل المجلموعات المجموعات & جودة المكان \\
\hline$\cdot, \cdot 1$ & $\Lambda, 11$ & $\begin{array}{l}1 r 90,0 \\
\text { irr, }\end{array}$ & $\begin{array}{l}1 \times 90,0 \\
1 A \cdot v 0, \& \\
19 \leqslant v \cdot, q\end{array}$ & $\begin{array}{l}1 \\
1.0 \\
1.7\end{array}$ & داخل المجين المجموعات & جودة الإتتاج \\
\hline
\end{tabular}

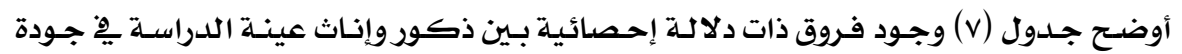

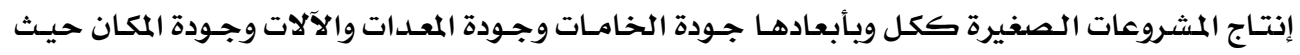

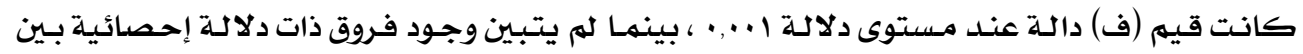

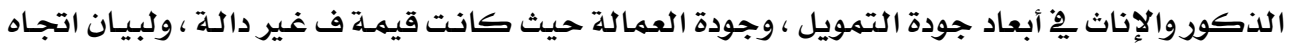

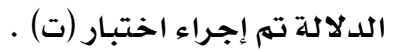


جدول ( 1 ) الفروق بين الذكور والإناث فِ جودة إنتاج المشروعات الصغيرة

\begin{tabular}{|c|c|c|c|c|c|c|c|}
\hline اتجاه الدلالة & مستوى الدلالة & قيمة ت & الخطأ المعياري & الانحراف المعياري & المتوسط الحسابي & \multicolumn{2}{|c|}{ المتفيرات } \\
\hline \multirow{2}{*}{ لصالج الذكور } & \multirow{2}{*}{$\cdot, \cdot+1$} & \multirow{2}{*}{$r, 79$} & •, or & $\{, 1$ & $r \cdot, \xi$ & ذكور & \multirow{2}{*}{ جودة الخامات } \\
\hline & & & •, $7 \varepsilon$ & $\mathfrak{\xi}, \wedge$ & IV,YY & إناث & \\
\hline \multirow{2}{*}{ لصالح الذكور } & \multirow{2}{*}{$\cdot, \cdot \cdot 1$} & \multirow{2}{*}{$r, 11$} & $\cdot, \mathrm{rA}$ & $r, \boldsymbol{\varepsilon}$ & 11, or & ذكور & \multirow{2}{*}{ جودة الآلات } \\
\hline & & & •, rr & $1, \Lambda$ & $1 \cdot, 19$ & إناث & \\
\hline \multirow{2}{*}{ لصالح الذكور } & \multirow{2}{*}{$\cdot, \cdot+1$} & \multirow{2}{*}{0,81} & $\cdot, r \xi$ & $r, r$ & $11, r \mu$ & ذكور & \multirow{2}{*}{ جودة المكان } \\
\hline & & & $\cdot, \mathrm{rA}$ & $1, r$ & $9, r \cdot$ & إناث & \\
\hline \multirow{2}{*}{ لصالح الذكور } & \multirow{2}{*}{$\cdot, \cdot \cdot 1$} & \multirow{2}{*}{ r, ro } & 1,79 & $\mathbb{I r}, \Lambda$ & vo,. & ذكور & \multirow{2}{*}{ جودة الإنتاج } \\
\hline & & & 1,91 & $1 T, 0$ & IV,V & إناث & \\
\hline
\end{tabular}

تبين من خلال جدول (^) أن الفروق بين الذكور والإناث ِِّ جـودة إنتاج المشروعات الصغيرة

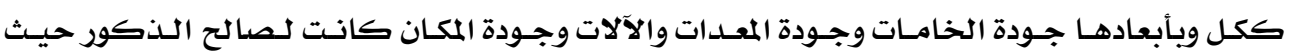

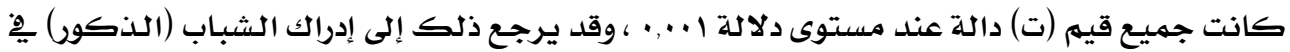

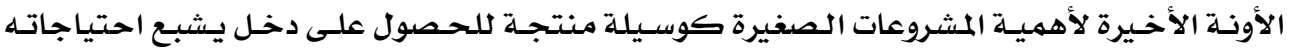

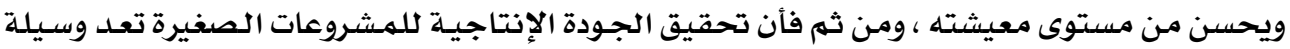

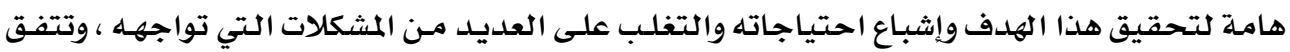

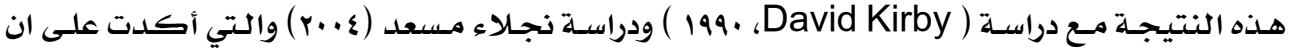

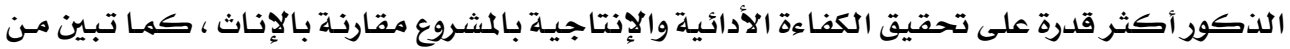

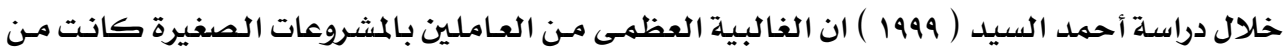

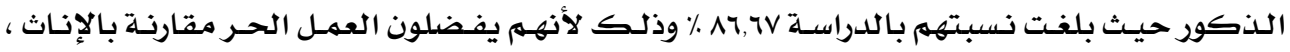

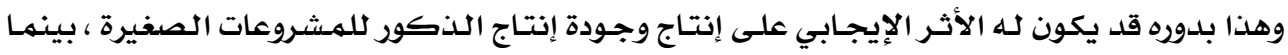

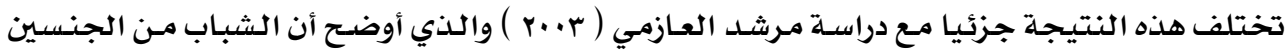

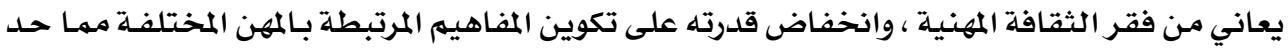

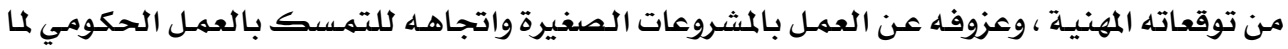

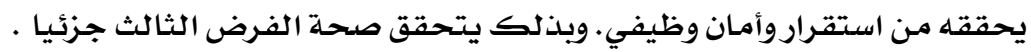

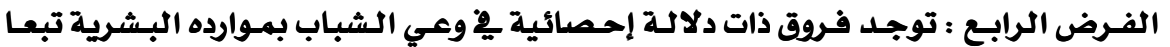
لاختلاف بعض متغيرات الدراسة ( مستوى تعليم الشاب - مستوي تعليم الوالدين - مستوى دخل

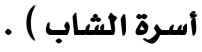

وللتعرف على الفروق قِّوعي الشباب بهوارده البشرية تبعا لاختلاف بعض متغيرات الدراسة

$$
\text { تم إجراء اختبار (ف) لتحليل التباين . }
$$


جدول ( 9 ) تحليل التباين يخ وعي الشباب بهوارده البشرية تبعا لاختلاف

( مستوى تعليهم الشاب ، مستوى تعليه الوالدين ، مستوى دخل الأسرة )

\begin{tabular}{|c|c|c|c|c|c|c|}
\hline مستوى الدلالة & قيمة ف & متوسط المربعات & مجموع المربعات & درجات الحرية & مصدر التباين & المتفيرات \\
\hline$\cdot, \cdot \cdot 1$ & $\Delta \xi, r r$ & $\begin{array}{l}\| r \xi \varepsilon, 0 \\
r \cdot, q\end{array}$ & $\begin{array}{l}11 r \varepsilon, 0 \\
\text { rlaq, } \\
\text { rrri,o }\end{array}$ & $\begin{array}{l}1 \\
1.0 \\
1.7\end{array}$ & داخل المين المجموعات & مستوى تعليم الشاب \\
\hline$\cdot, \cdot+1$ & 71,1 & $\begin{array}{l}\wedge 99, q \\
1 \xi, Y\end{array}$ & $\begin{array}{l}\text { IVA9,A } \\
\text { IOrI,Y } \\
\text { rrTI,O }\end{array}$ & $\begin{array}{l}r \\
1.8 \\
1.9\end{array}$ & داخل المجن المجموعات & مستوى تعليي الأب \\
\hline$\cdot, \cdot \bullet 1$ & $\| \Lambda, r$ & $\begin{array}{l}\text { llov, } \\
q, \gamma\end{array}$ & $\begin{array}{l}\text { rrIE, } \\
1.1 V, \varepsilon \\
\text { rrri,o }\end{array}$ & $\begin{array}{l}r \\
1.8 \\
1.9\end{array}$ & داخل المين المجموعات & مستوى تعليم الأم \\
\hline$\cdot, \cdot+1$ & $1 \cdot \wedge, \Lambda$ & $\begin{array}{l}11 r q, q \\
1 \cdot, 8\end{array}$ & $\begin{array}{l}\text { rror,q } \\
\text { 1.rr, } 9 \\
\text { rrrt,o }\end{array}$ & $\begin{array}{l}r \\
1.8 \\
1.9\end{array}$ & 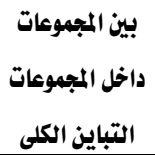 & متوسط دخل الأسرة \\
\hline
\end{tabular}

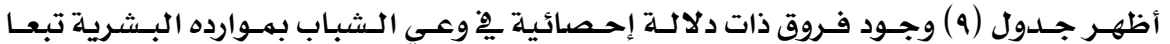

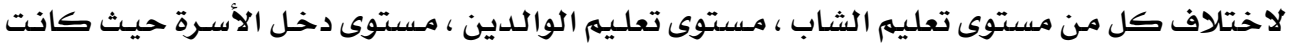

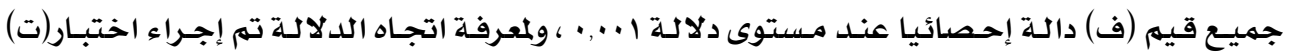

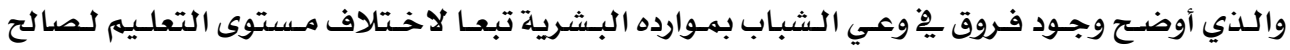

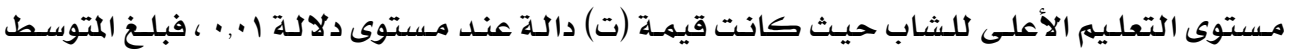

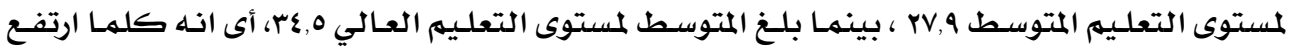

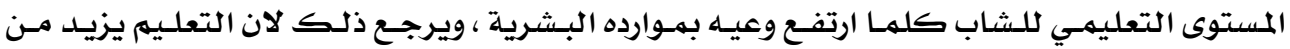

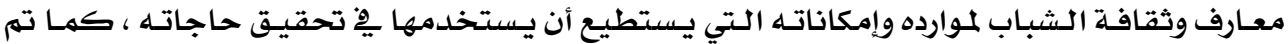

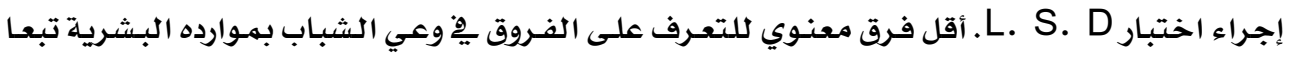

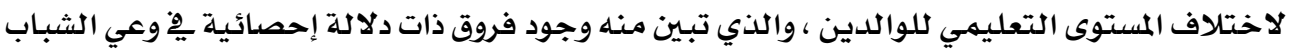

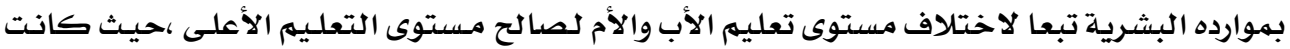

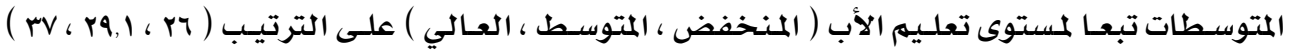

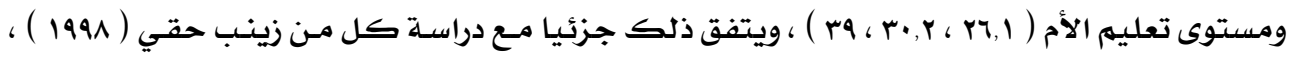

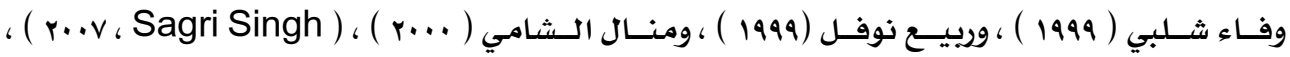

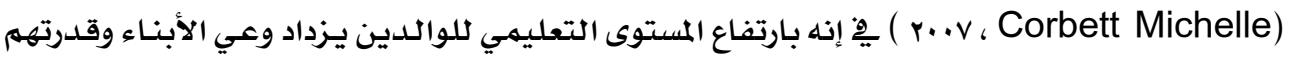

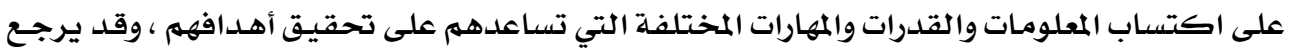

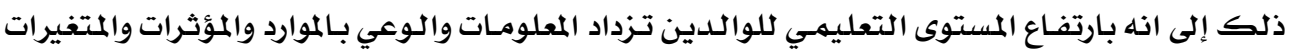




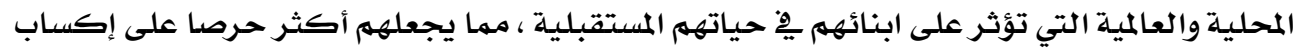

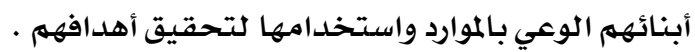

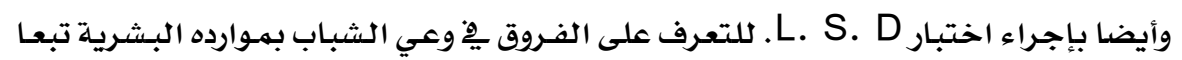

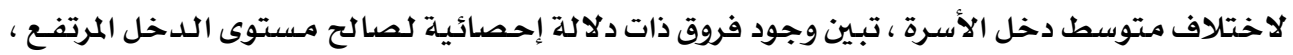

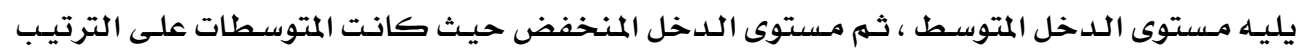

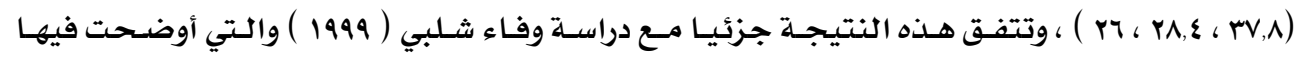

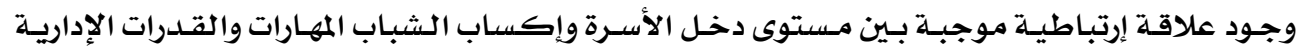

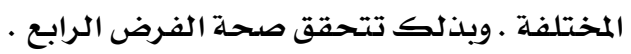

الفرض الخامس : توجد فروق ذات دلالة إحصائية يِ جودة إنتاج المثروعات الصغيرة تبعا لاختلاف بعض متغيرات الدراسة ( مستوى تعليم الشاب - مستوي تعليم الوالدين - مستوى دخل

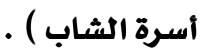

وللتحقق من صحة هذا الفرض تم إجراء اختبار ( ف ) لتحليل التباين .

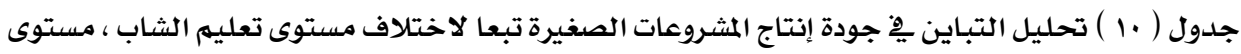

\begin{tabular}{|c|c|c|c|c|c|c|}
\hline مستوى الدلالة & قيمة ف & متوسط المربعات & مجموع المربعات & درجات الحرية & مصدر التباين & المتفيرات \\
\hline$\cdot, \cdot \cdot 1$ & $\Delta \wedge, \xi$ & $\begin{array}{l}7909, r \\
119, r\end{array}$ & $\begin{array}{l}7909, r \\
1 r 011,7 \\
1987 \cdot, 1\end{array}$ & $\begin{array}{l}1 \\
1.0 \\
1.7\end{array}$ & داخل المجلموعات المجوعات & مستوى تعليم الشاب \\
\hline$\cdot, \cdot \cdot 1$ & $\mid \xi \varepsilon, 1$ & $\begin{array}{l}\text { vior,Y } \\
\varepsilon 9, Y\end{array}$ & $\begin{array}{l}1 \xi T \cdot Y, r \\
017 r, 0 \\
19 \& V \cdot, q\end{array}$ & $\begin{array}{l}r \\
1.8 \\
1.9\end{array}$ & داخل المجاين المجموعات & مستوى تعليه الأب \\
\hline$\cdot, \cdot \cdot 1$ & $1 \cdot v, 11$ & $\begin{array}{l}\text { 700r, } Y \\
71,1\end{array}$ & $\begin{array}{l}|r| \cdot v, \xi \\
\eta r q r, \xi \\
\mid 9 \& \% \cdot, \wedge\end{array}$ & $\begin{array}{l}r \\
1.8 \\
1.9\end{array}$ & داخل المجن المجموعات & مستوى تعليم الأم \\
\hline$\cdot, \cdot \cdot 1$ & १४, १ & $\begin{array}{l}7 r 0 \cdot, 1 \\
70,1\end{array}$ & $\begin{array}{l}1 r v \cdot 1, q \\
7 Y 7 q, r \\
19 \& r \cdot, q\end{array}$ & $\begin{array}{l}r \\
1.8 \\
1.9\end{array}$ & داخل المجن المجموعات & متوسط دخل الأسرة \\
\hline
\end{tabular}

أظهـر جـدول ( . ) وجـود فروق ذات دلالـة إحصائية يِّ جـودة إنتاج المشروعات الصغيرة تبعـا

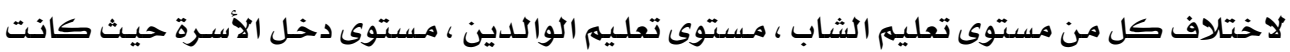

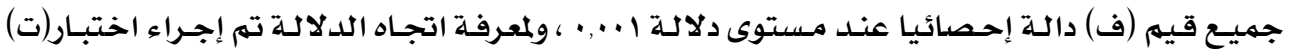

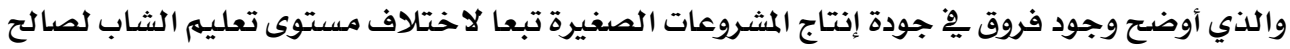

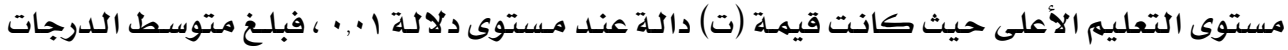




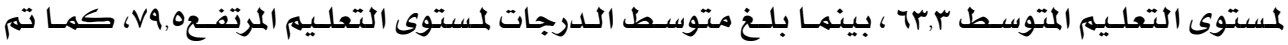

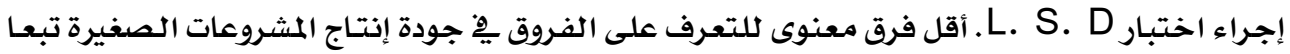

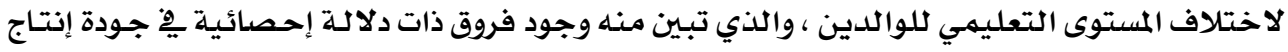

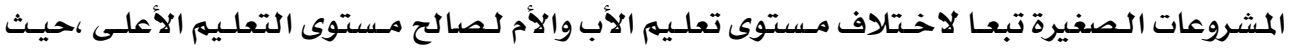

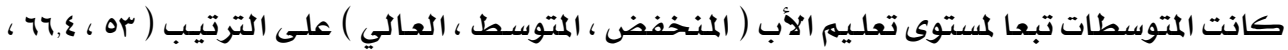

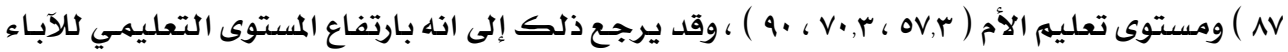

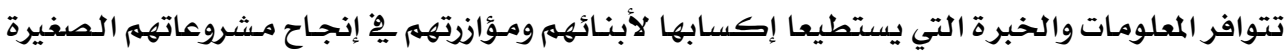

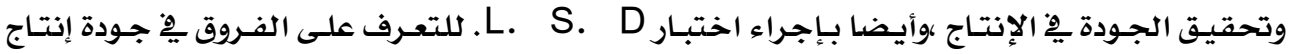

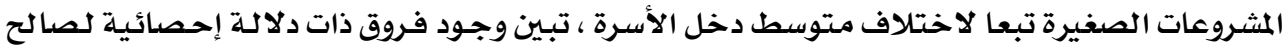

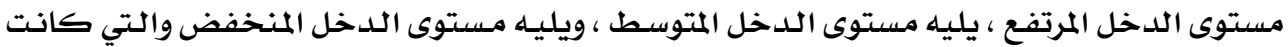

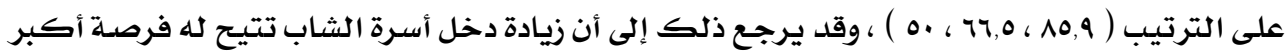

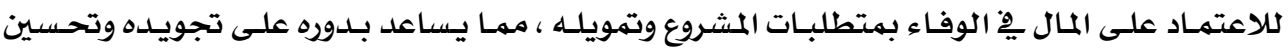

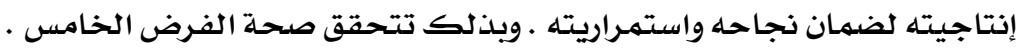

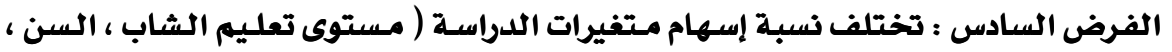

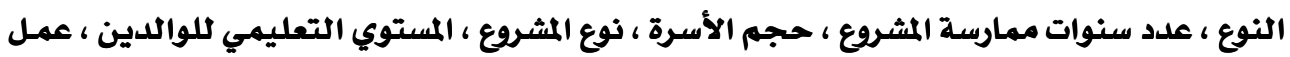

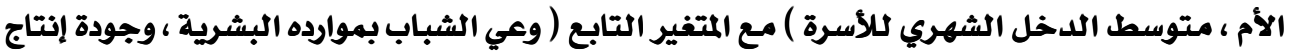

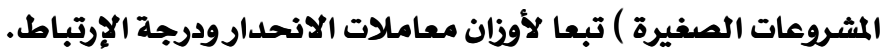
وللتحقق من صـحة هـذا الفـرض تم اسـتخدام معامـل الانحسدار المتعـدد ، باستتخدام الخطوة

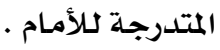

جدول ( 11 ) معاملات الانحدار باستخدام الخطوة المتدرجة إلى الأمام ( Step wise )

\begin{tabular}{|c|c|c|c|c|c|c|}
\hline مستوى الدلالة & قيمة ف & $\begin{array}{c}\text { B } \\
\text { معامل الانحدار }\end{array}$ & $\begin{array}{c}\text { R2 } \\
\text { نسبة المشاركة }\end{array}$ & $\begin{array}{c}\text { R } \\
\text { معامل الارتباط }\end{array}$ & المتفير المستقل & التففير التابع \\
\hline$\cdot, \cdot \cdot 1$ & 147,9 & $\varepsilon, \boldsymbol{r}$ & • & $\cdot, \wedge$ & مستوى تعليم الأم & وعى الشباب \\
\hline$\cdot, \cdot \cdot 1$ & $r \xi, q$ & $r, q$ & $\cdot, n$ & $\cdot, \wedge \varepsilon$ & متوسط دخل الأسرة & بالموارد البشرية \\
\hline$\cdot, \cdot \cdot 1$ & $\mathbf{M}, \boldsymbol{\varepsilon}$ & 1,1 & $\cdot$, ro & $\cdot, \wedge 9$ & عدد سنوات ممارسة الشرروع & \\
\hline$\cdot, \cdot \cdot 1$ & $r \xi, \Lambda$ & $r, r$ & $\cdot, \wedge \cdot$ & $\cdot, \wedge 9$ & عمل الأم & \\
\hline$\cdot, \cdot 0$ & $r, q$ & $1, r$ & $\cdot, \wedge 1$ & $\cdot, 9$. & مستوى تعليم الشاب أو الفتاة & \\
\hline$\cdot, \cdot \cdot 1$ & rqa, & $|\xi|$, & $\cdot, r$ & $\cdot, \wedge \xi$ & مستوى تعليم الأب & جودة إتتاج \\
\hline$\bullet, \cdot \cdot 1$ & 01,0 & 7,9 & $\cdot, \wedge 1$ & $\cdot, 9 \cdot$ & النوع النوع & الشروعات \\
\hline$\cdot, \cdot \cdot 1$ & $\varepsilon 0, \vee$ & $r, \wedge$ & $\cdot, A r$ & •, ar & علد سنوات ممارسة الششروع & الصفيرة \\
\hline$\cdot, \cdot \cdot 1$ & $10, r$ & $r, 0$ & $\cdot, \wedge \wedge$ & •,qr & عمل الأم & \\
\hline$\cdot, \cdot 1$ & $\xi, \varepsilon$ & $r, 0$ & $\cdot, 19$ & , १ई & مستوى تعليم الشاب أو الفتاة & \\
\hline
\end{tabular}


يتضح من الجدول السـابق أن مستوى تعليم الام كـان أهـم المتغيرات التي أدخلت فِّ تحليل

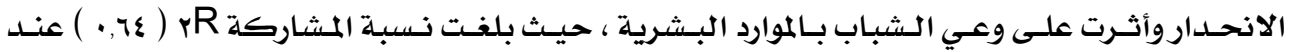

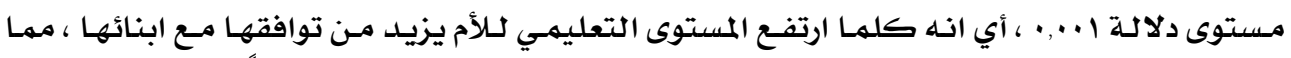

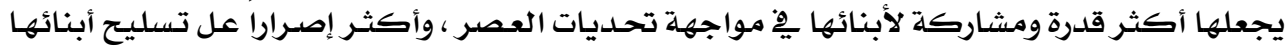

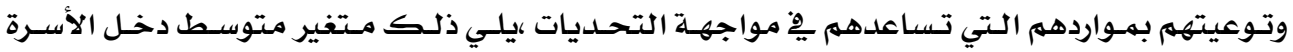

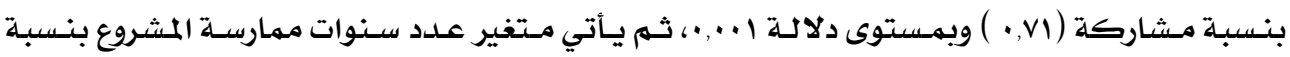

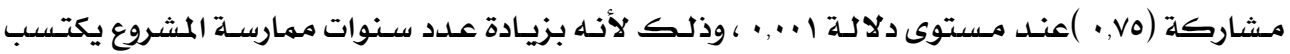

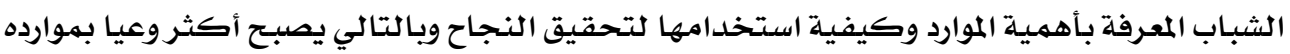

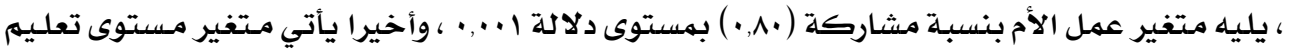

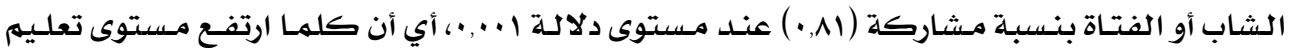

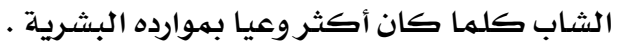

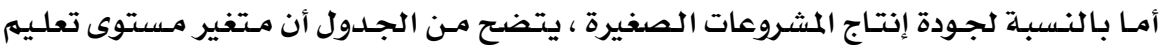

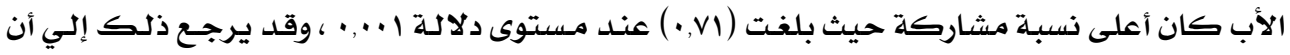

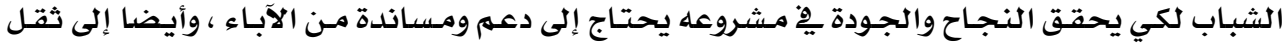

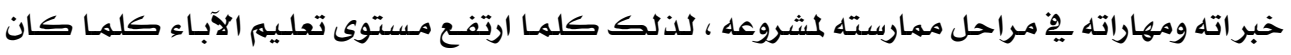

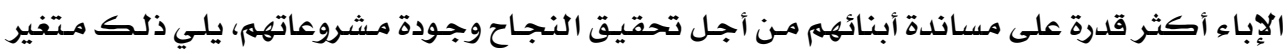

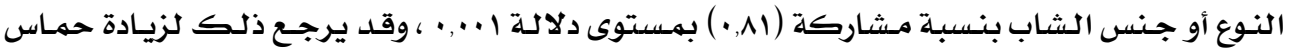

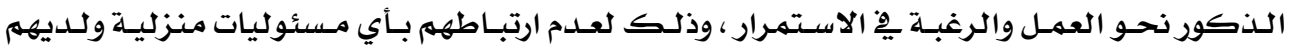

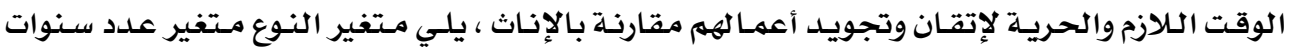

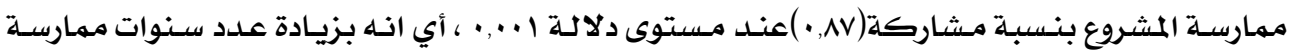

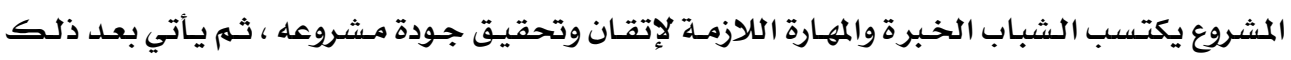

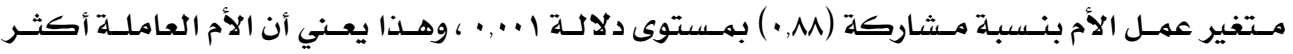

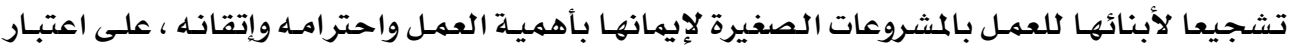

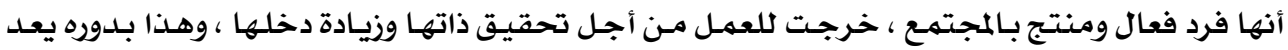

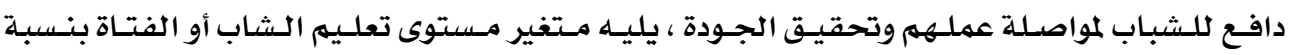

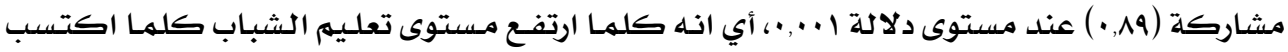

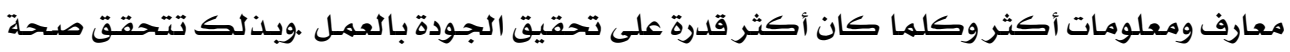

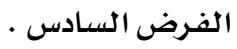

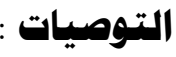

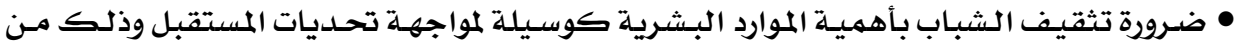
خـلال إعـداد وتطبيـق البر امج الفعالـة لإكسـاب الشبـاب الـوعي بمـوارده وأسـاليب اسـتثمارها 


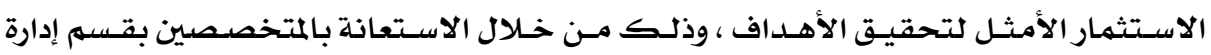

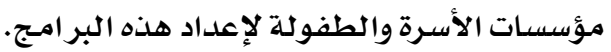

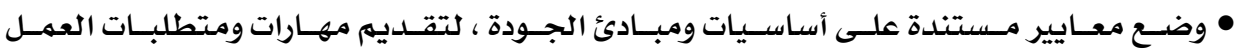

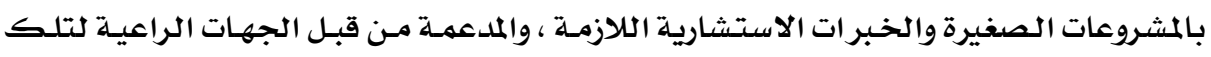

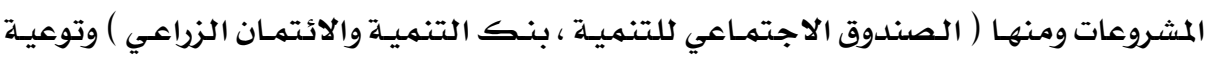

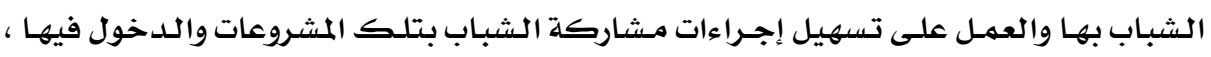

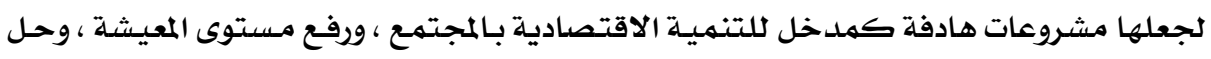

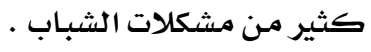

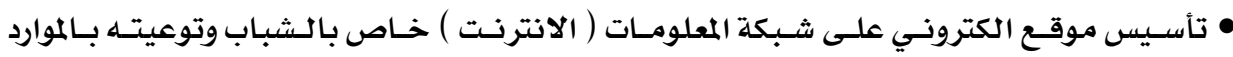

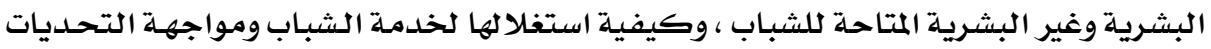

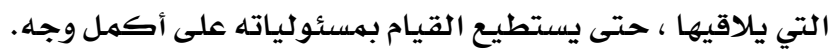

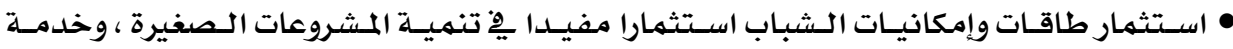

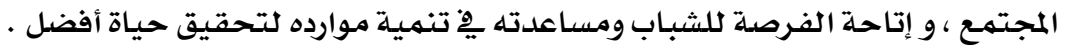

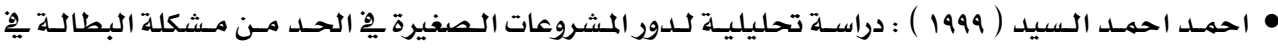

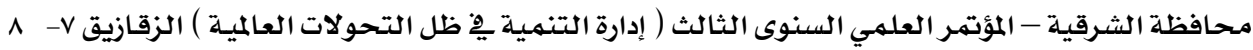
نزفمبر •

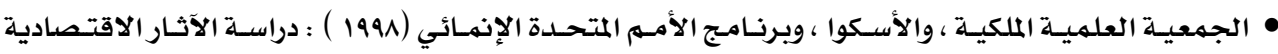

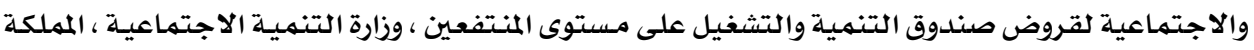

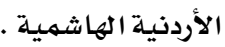

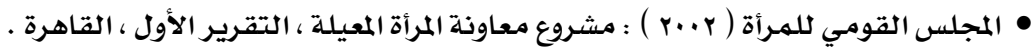

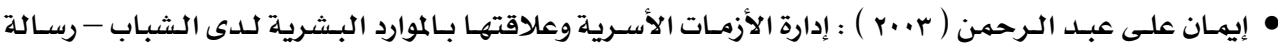

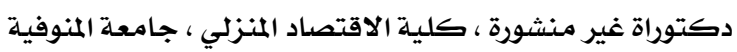

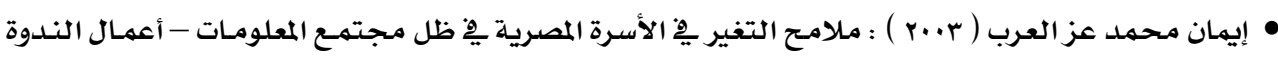

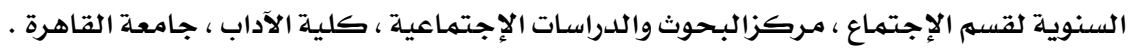

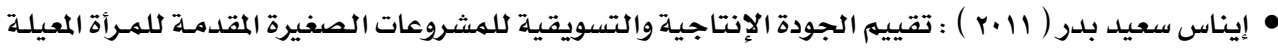

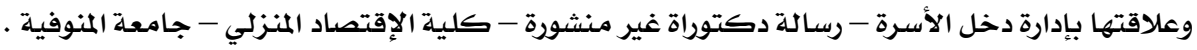

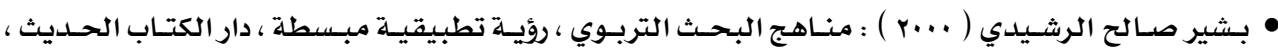

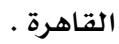

• بثينة عمارة ( r . . ) ) : العولمة وتحديات العصر وانعكاساتها على المجتمع المصري - دار الامـين - القاهرة .

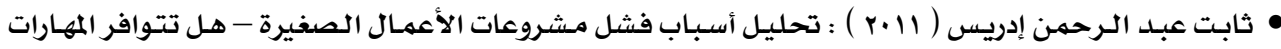

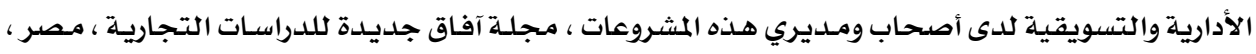

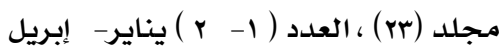


• ربيع محمود على نوفل ( 1999 ) : تخطيط ريسة الأسرة لمواردها وعلاقته بهستوى الوعي بقيمسة الموارد الماديـة

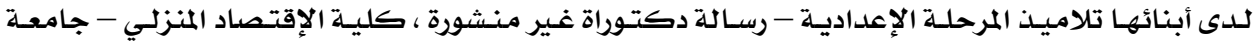
المنوفية .

• زينب محمد حسين حقي ( 1991 ) : أثر التخطيط الأسري يٌْ مواجهة صراع الدور لدى ربـة الأسرة العاملة -

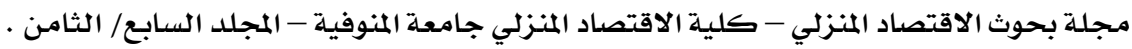

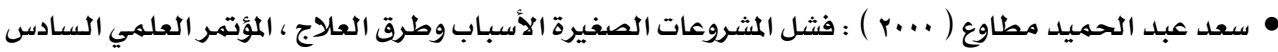

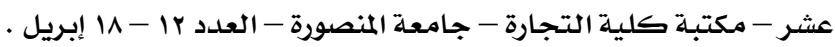

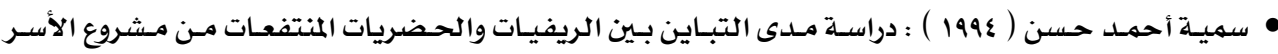

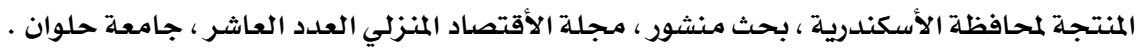

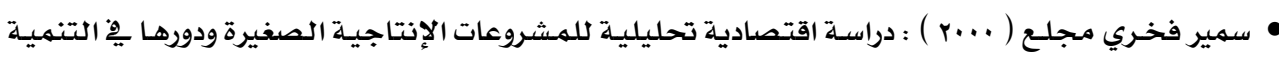

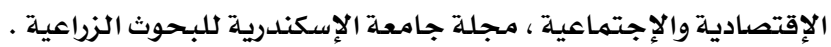

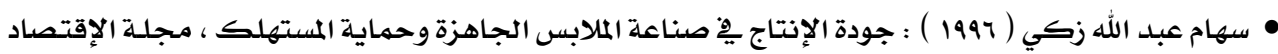

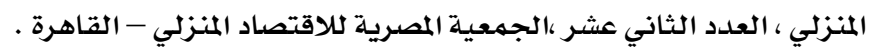

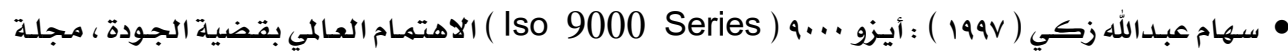
الاقتصاد المنزلي - العدد الثالث عشر ، الجمعية المصرية للاقتصاد المنزلي - القاهرة .

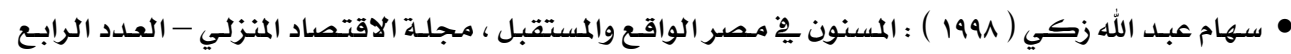
عشر ، الجمعية المصرية للاقتصاد المنزلي - القاهرة

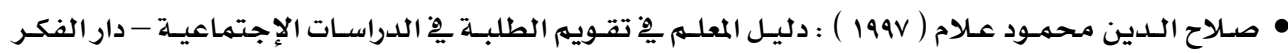
العربي - القاهرة

• محمد توفيق ماضي ( 1990 ) : إدارة الجودة - مدخل النظام المتكامل - دار المعارف ، القاهرة .

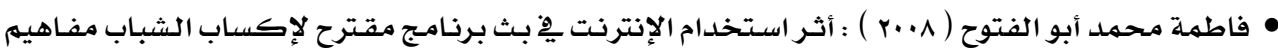

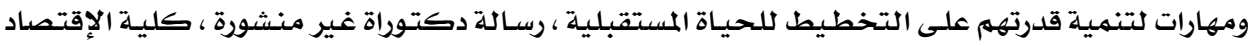

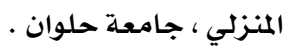

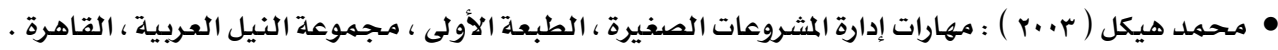

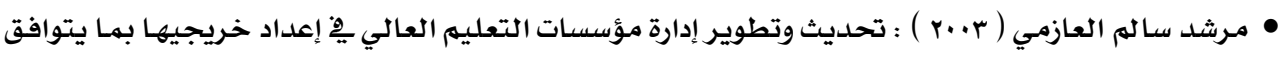

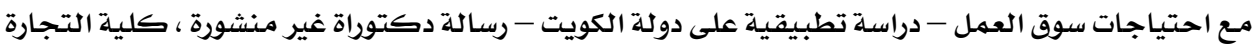

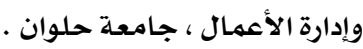

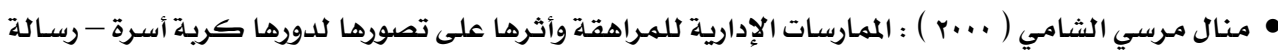

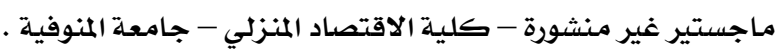

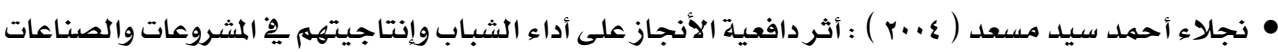

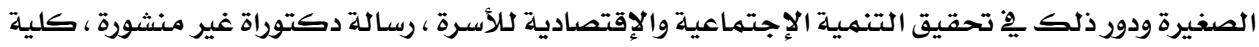




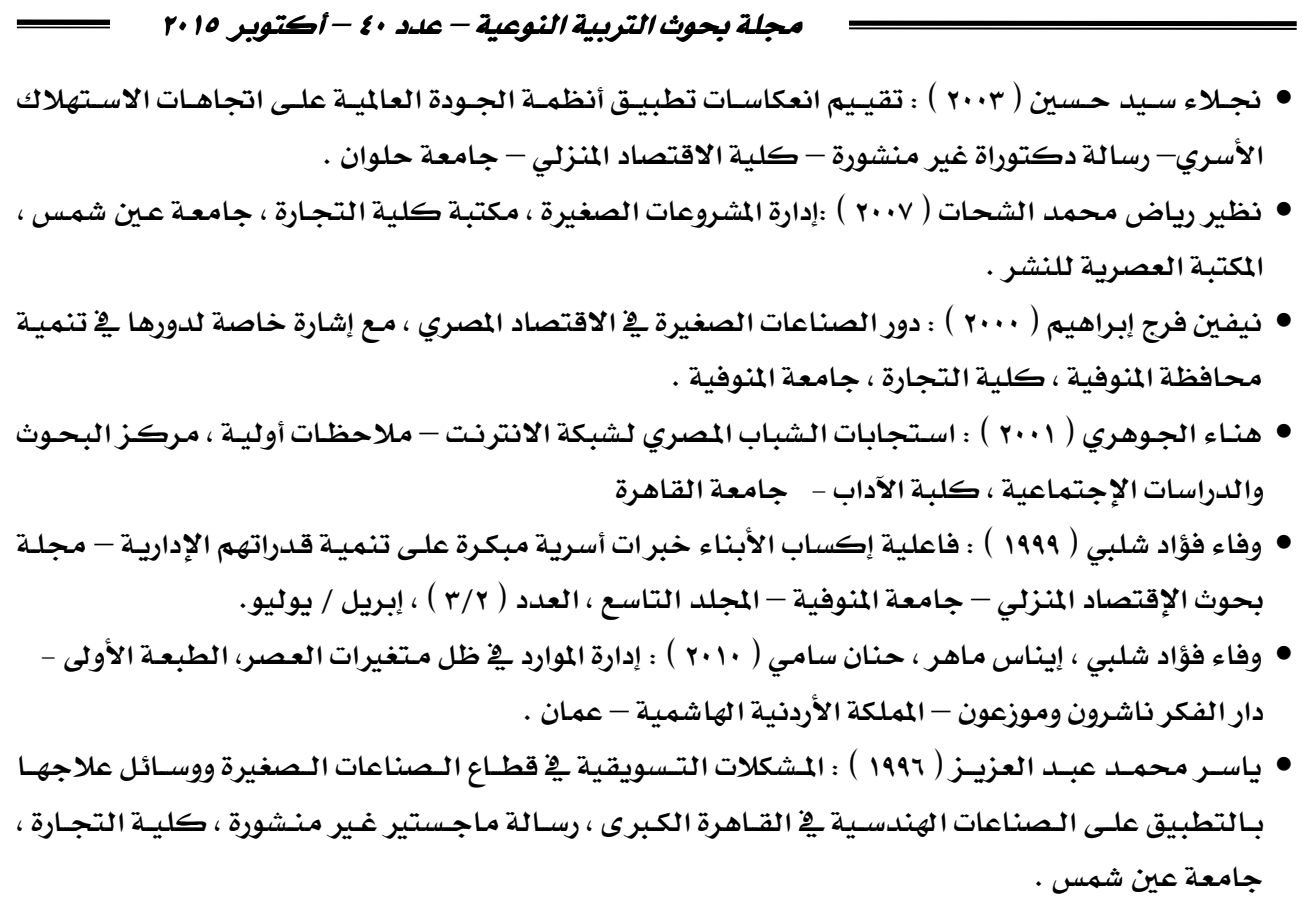

- Brain. E. M\& Michalasr( 1989 ) : Total Quality management, LMI - New York.

- Corbett Michelle, ( 2007 ) : Factors affecting choice of contraceptive method among young women-southern, Connecticut state university.

- David, L. G\& .Starly, D. (1994) :Intrernational to total quality, U. S. A, Macmillan Collage Publishing Company.

- Donald, W.( 1991) : Marketing Strategies of smal Industrial Manufactures, Industrial Marketing Management, Vol.20.

- Durham Wesley T. ( 2004 ) : The family planning communication of voluntarity Child - Free. C0uples, Dissertation Abstracts International, Vol. 65, no.1

- Gvence, G. (1990) : Managerial Isues and Problem Solving in the Formative Years, Journal of small business management, vol. 28, 2, April .

- Johon Muni ( 2000 ) : Youth and crime A critical introduction, library cataloguing pup, London.

- Johnson, Peroy. L. ( 1993 ): ISO 9000 , Meeting the new international standards. MC Graw - Hill, New York.

- Kirby David A. ( 1990 ) : Management Education and small business development : An Exploratoratory study of small firm in the U.K., journal of small business management, vol. 28. No 1, October. 


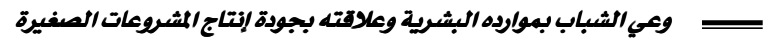

- Singh- Sagri, ( 2007 ) : Primarital family role, family planning information in fertility and contraceptive use among rural women in India - The johns Hopkins university.

- Soewon ‘H. S. ( 1998 ) : The Interrelation ship Between IsoGoodland CMM for Software Version (Quality management) California State, State, university Dominguez, Hills. 


\title{
Youth's awareness of human resources and its relationship with quality production of small projects
}

\author{
DR. Hanan Samy Mohamed Abdel-Atti*
}

\section{Study summary}

The present study aimed to reveal the relationship between youth's awareness, who are working in small projects, with human resources and quality production of small projects with dimensions ( financing quality, the quality of raw materials ،quality of equipment and machinery, labor quality and quality of place. (The study also investigated the differences in the youth's awareness with its human resources and the differences in the quality production of small projects according to difference of some variables of the study ( sex - level of education of the youths - the level of parental education - average income of family). Sample of the study involved 107 youths ( males and females ) from different social and economic levels of the people in Cairo and Giza governorates .The general data statements, a questionnaire of awareness with human resources and a questionnaire of quality production of small projects were designed and applied.

The attained results showed that there is a positive correlation between youth's awareness with human resources and the quality production of small projects. There are differences between males and females in the awareness of human resources and the quality production of small projects, at the level of significance $0.001,0.01$, respectively in favor of males. There are significant differences ( at level of significance of 0.001 and 0.01 ) in the awareness of human resources and the quality production of small projects according to level of youth's education, level of parental education and the average of family income in favor of the highest level of youth's education, the highest level of parent's education and the highest income of family. It was found that the most important variables affecting in youth's awareness with its human resources were the level of mother's education, average income of family, number of years of practice project, mother's work and level of youth's education, respectively. Whereas, the father's education level, sex, number of years of practice project, mother's work and youth's education level were the most important variables affecting in quality production of small projects.

\footnotetext{
* Assistant professor in department of managing the family and childhood institutions Home economics faculty, Helwan university 